\title{
Ionic Mechanisms of Burst Firing in Dissociated Purkinje Neurons
}

\author{
Andrew M. Swensen and Bruce P. Bean \\ Department of Neurobiology, Harvard Medical School, Boston, Massachusetts 02115
}

Cerebellar Purkinje neurons have intrinsic membrane properties that favor burst firing, seen not only during complex spikes elicited by climbing fiber input but also with direct electrical stimulation of cell bodies. We examined the ionic conductances that underlie all-ornone burst firing elicited in acutely dissociated mouse Purkinje neurons by short depolarizing current injections. Blocking voltagedependent calcium entry by cadmium or replacement of external calcium by magnesium enhanced burst firing, but it was blocked by cobalt replacement of calcium, probably reflecting block of sodium channels. In voltage-clamp experiments, we used the burst waveform of each cell as a voltage command and used ionic substitutions and pharmacological manipulations to isolate tetrodotoxin (TTX)sensitive sodium current, P-type and T-type calcium current, hyperpolarization-activated cation current $\left(I_{\mathrm{h}}\right)$, voltage-activated potassium current, large-conductance calcium-activated potassium current, and small-conductance calcium-activated potassium (SK) current. Measured near the middle of the first interspike interval, TTX-sensitive sodium current carried the largest inward current, and T-type calcium current was also substantial. Current through P-type channels was large immediately after a spike but decayed rapidly. These inward currents were opposed by substantial components of voltage-dependent and calcium-dependent potassium current. Termination of the burst is caused partly by decay of sodium current, together with a progressive buildup of SK current after the first interspike interval. Although burst firing depends on the net balance between multiple large currents flowing after a spike, it is surprisingly robust, probably reflecting complex interactions between the exact voltage waveform and voltage and calcium dependence of the various currents.

Key words: resurgent sodium current; $\mathrm{Na}^{+}$channel; $\mathrm{Ca}^{2+}$ channel; $\mathrm{T}$-type channel; complex spike; action potential clamp

\section{Introduction}

Cerebellar Purkinje neurons often fire action potentials in closely spaced bursts. This is most evident in complex spikes, bursts of action potentials riding on the large depolarization resulting from climbing fiber stimulation (Eccles et al., 1966). Burst firing can occur spontaneously (Cingolani et al., 2002; Womack and Khodakhah, 2002b), however, and can also be elicited by depolarizing current injections or anode break in cerebellar slices (Callaway and Ross, 1997), in dissociated tissue culture (Gruol and Franklin, 1987; Gruol et al., 1992), and in slice culture (Cavelier et al., 2002). Furthermore, acutely dissociated Purkinje neurons produce all-or-none bursts in response to brief injections of current (Raman and Bean, 1997). Thus, burst firing likely reflects intrinsic membrane properties of Purkinje neurons.

A number of ionic conductances contribute to burst firing in various neurons. These include the hyperpolarization-activated cation current, $I_{\mathrm{h}}$ (Pape, 1996; Luthi et al., 1998), T-type calcium channels (Jahnsen and Llinás, 1984; White et al., 1989; Huguenard and Prince, 1992), calcium-activated nonselective cation channels (Hasuo et al., 1990; Haj-Dahmane and Andrade, 1997), and voltage-dependent sodium channels (Azouz et al., 1996;

\footnotetext{
Received Jan. 22, 2003; revised Aug. 26, 2003; accepted Sept. 3, 2003.

This work was supported by the National Institutes of Health (NS38312).

Correspondence should be addressed to Andrew M. Swensen, Department of Neurobiology, Harvard Medical School, 220 Longwood Avenue, Boston, MA 02115. E-mail: andrew_swensen@hms.harvard.edu.

Copyright $\odot 2003$ Society for Neuroscience $\quad$ 0270-6474/03/239650-14\$15.00/0
}

Brumberg et al., 2000; Washburn et al., 2000). Most investigations of burst firing have tested the effect of blockers in current clamp, but interpretation is difficult, because blocking one current changes the voltage trajectory, producing indirect effects on all other voltage-gated conductances. This problem makes it hard to assess the relative contributions of multiple currents to burst firing. It is also difficult to establish the degree of selectivity of blockers in current-clamp experiments, and most often the selectivity has to be assumed rather than tested.

A more direct approach is offered by the action potential clamp method (Llinás et al., 1982; de Haas and Vogel, 1989), in which an action potential waveform is used as the command voltage in voltage-clamp experiments. Applying this method to isolated Purkinje neurons showed that tetrodotoxin (TTX)sensitive sodium current flows between the spikes of bursts ( $\mathrm{Ra}$ man and Bean, 1997); this current is at least partly "resurgent" sodium current, which flows after repolarization following short, large depolarizations (Raman and Bean, 1997, 2001). In null mutants for the NaV1.6 $\alpha$ subunit of sodium channels, in which resurgent sodium current is greatly reduced, burst firing is truncated (Raman et al., 1997). It is not eliminated completely, however, suggesting the additional involvement of other currents, although there is also a possibility of compensatory changes during development of the mutant animals.

We explored the magnitude and timing of various ionic currents during bursts in dissociated Purkinje neurons using the 
action potential clamp method. We found that T-type calcium current and subthreshold sodium current are both substantial throughout the interspike interval. Current from $I_{\mathrm{h}}$ is very small, and P-type calcium current is large immediately after spikes but decays quickly. The major opposing potassium current between spikes is the large-conductance calcium-activated potassium current $(\mathrm{BK})$. Although small-conductance calcium-activated potassium current (SK) is smaller, it increases progressively during bursts and plays an important role in regulating burst duration.

\section{Materials and Methods}

Cell preparation. Experiments were performed on cerebellar Purkinje neurons enzymatically isolated with dissociation techniques similar to those described previously (Mintz et al., 1992b; Raman et al., 1997). Black Swiss mice (postnatal day 13-17) were anesthetized with isoflurane (Abbott Laboratories, North Chicago, IL) and decapitated, and cerebella were dissected out and minced in ice-cold dissociation solution containing (in mM): $82 \mathrm{Na}_{2} \mathrm{SO}_{4}, 30 \mathrm{~K}_{2} \mathrm{SO}_{4}, 5 \mathrm{MgCl}_{2}, 10$ HEPES, 10 glucose, and $0.001 \%$ phenol red, buffered to $\mathrm{pH} 7.4$ with $\mathrm{NaOH}$. The tissue was then transferred to $10 \mathrm{ml}$ of room temperature dissociation solution containing $2.5 \mathrm{mg} / \mathrm{ml}$ protease XXIII, pH 7.4 with $\mathrm{NaOH}$, and subsequently incubated at $33^{\circ} \mathrm{C}$ for $7-9 \mathrm{~min}$. After incubation, the tissue was washed in ice-cold dissociation solution containing $1 \mathrm{mg} / \mathrm{ml}$ bovine serum albumin and $1 \mathrm{mg} / \mathrm{ml}$ trypsin inhibitor and then maintained on ice in either dissociation solution or a solution containing (in $\mathrm{mm}$ ): $150 \mathrm{NaCl}, 4 \mathrm{KCl}$, $2 \mathrm{CaCl}_{2}, 2 \mathrm{MgCl}_{2}, 10$ HEPES, 10 glucose, $\mathrm{pH} 7.4$ with $\mathrm{NaOH}$. Tissue was withdrawn as needed and triturated with a fire-polished Pasteur pipette to liberate individual neurons. Purkinje cells were identified by their large diameter and characteristic pear shape attributable to the stump of the dendritic tree.

Electrophysiology. Recordings were made using an Axopatch 200A amplifier (Axon Instruments, Foster City, CA). Electrodes were pulled from borosilicate glass micropipettes (VWR Scientific, West Chester, PA) and had resistances from 1.5 to $3 \mathrm{M} \Omega$ when filled with the internal solution, which consisted of (in $\mathrm{mm}$ ): $122 \mathrm{KGluconate,} 9 \mathrm{NaCl}, 1.8 \mathrm{MgCl}_{2}, 0.9$ EGTA, 9 HEPES, 14 Tris-creatine $\mathrm{PO}_{4}, 4$ MgATP, 0.3 Tris-GTP, pH 7.4 with $\mathrm{KOH}$. Electrode shanks were wrapped with Parafilm (American National Can Corporation, Greenwich, CT) to within several hundreds of micrometers of the tip to reduce capacitance. Reported membrane potentials were corrected for a $-10 \mathrm{mV}$ liquid junction potential between the internal solution and the Tyrode's solution in which current was zeroed before sealing onto the cell, measured using a flowing $3 \mathrm{M} \mathrm{KCl}$ bridge as described by Neher (1992).

Under some circumstances, intracellular Kgluconate may inhibit some ion channels, including calcium-activated potassium channels (Velumian et al., 1997). To evaluate this possibility, we also performed some recordings using 135 Kmethanesulfonate in place of Kgluconate. There was no obvious difference in Purkinje cell bursting or in the amplitude of the SK current ( $37 \pm 10 \mathrm{pA} / \mathrm{pF}$ in Kgluconate, $n=6$, vs $32 \pm$ $14 \mathrm{pA} / \mathrm{pF}$ in Kmethanesulfonate, $n=3$ ) elicited from steps to $-15 \mathrm{mV}$. There was also no difference in the amplitude of BK current $(254 \pm 58$ $\mathrm{pA} / \mathrm{pF}$ in Kgluconate, $n=7$, vs $279 \pm 50 \mathrm{pA} / \mathrm{pF}$ in Kmethanesulfonate, $n=3)$. We also did some recordings with lower EGTA (0.1 and $0.2 \mathrm{~mm}$ ), but we found that 0.9 EGTA best replicated the bursting activity in individual cells when it was seen in an "undisturbed" condition in cellattached patches (see Fig. 9). With 0.9 mM EGTA, bursting remained very consistent throughout recording sessions, whereas with lower EGTA bursting was often diminished or eliminated soon after breakthrough.

After the whole-cell recording was established, cells were lifted and placed in front of a row of flow pipes. The control physiological Tyrode's solution consisted of (in mM): $155 \mathrm{NaCl}, 4 \mathrm{KCl}, 2 \mathrm{CaCl}_{2}, 2 \mathrm{MgCl}_{2}, 10$ HEPES, pH 7.4 with $\mathrm{NaOH}$. The recording mode of the amplifier was switched to the fast current-clamp mode, and steady holding current was applied to hyperpolarize the cells enough to stop the spontaneous firing that was normally present with no current injection. Cells were typically hyperpolarized to near $-90 \mathrm{mV}$. The fast current-clamp mode is necessary to reduce distortion of action potentials observed when patch-clamp amplifiers are used in current-clamp mode (Magistretti et al., 1996,
1998). We could routinely use fast current-clamp mode with the relatively low-resistance pipettes that we used (1.5-3 $\mathrm{M} \Omega$ ) as long as the shanks were wrapped with Parafilm to reduce capacitance. Without wrapping, oscillations occur in fast current-clamp mode with electrode resistances below $\sim 5 \mathrm{M} \Omega$. Action potentials were elicited by a series of 1 msec current injections of incrementing amplitude, which elicited all-ornone firing of a burst. The amplifier was then switched to voltage-clamp mode, with the recorded burst used as command voltage. In voltageclamp mode, cell capacitance was nulled electronically using the circuitry in the amplifier, and series resistance, which ranged from 2 to $5 \mathrm{M} \Omega$, was compensated by $75-90 \%$.

Cells were then moved between the series of flow pipes containing different solutions, and the command waveform was repeated in each solution. Individual ionic currents were derived from subtractions of responses obtained under different ionic and pharmacological conditions. For recording sodium current, reduced $\mathrm{NaCl}$ ( $50 \mathrm{~mm}$ ) was used to minimize series resistance errors. $\mathrm{NaCl}$ was partially replaced by TEACl (105 mM), which blocked the majority of potassium current, both voltage- and calcium-activated, and facilitated accurate TTX subtraction. Sodium current was obtained as the current sensitive to TTX (1-3 $\mu \mathrm{M})$. Solutions for recording calcium current by $\mathrm{Mg}^{2+}$ replacement of $\mathrm{Ca}^{2+}$ also contained $105 \mathrm{~mm}$ TEA to block potassium currents. The effects of solution changes were complete within $1 \mathrm{sec}$ when only ions were being changed. The effects of $\omega$-Aga-IVA (100-300 nM), mibefradil (1-10 $\mu \mathrm{M})$, iberiotoxin (100-150 nM), apamin (100-200 nM), and scyllatoxin (30 $\mathrm{nM}$ ) were slower, and these solutions were applied until steady-state effects were reached. Mibefradil was always applied after $\omega$-Aga-IVA had blocked P-type calcium current, to minimize errors from the effect of mibefradil on P-type channels, which at some voltages are partially blocked by the concentrations of mibefradil required to completely block T-type current (McDonough and Bean, 1998). All experiments were done at room temperature. It would be desirable to examine possible differences in ionic currents and bursting at physiological temperatures; both the magnitude and resting availability of T-type calcium current are larger at $35^{\circ} \mathrm{C}$ than at room temperature (McDonough and Bean, 1998), which could enhance bursting. We attempted a series of experiments at $35^{\circ} \mathrm{C}$ but found that the lifetime of the cells during a recording was much shorter than at room temperature, and it was not feasible to complete the experimental protocol while cells remained optimally healthy.

The reversal potential for sodium channel current with the $50 \mathrm{~mm}$ $\mathrm{Na}^{+}$external solution was approximately $+28 \mathrm{mV}$ (see Fig. 3), consistent with the Goldman-Hodgkin-Katz equation using a permeability ratio of potassium to sodium $\left(P_{\mathrm{K}} / P_{\mathrm{Na}}\right)$ of 0.07 (Hille, 2001a), which predicts a reversal potential of $+26 \mathrm{mV}$ with our solutions. Thus, when sodium current was recorded using the spike waveforms, it was outward at the peaks of the action potentials, which were recorded in current clamp using $155 \mathrm{~mm}$ sodium and typically had peaks near +40 to $+50 \mathrm{mV}$.

To quantify each ionic current during the interspike interval, we calculated average current over a $1 \mathrm{msec}$ window, starting $1.5 \mathrm{msec}$ after the trough of the spike. This generally corresponded to near the middle of the first interspike interval. To examine how currents change during the burst, we also calculated current in $1 \mathrm{msec}$ intervals starting $1.5 \mathrm{msec}$ after subsequent spike troughs in the burst. In the series of experiments examining BK and SK currents (see Figs. 12, 13), the particular neurons studied were unusually "bursty," firing (in control conditions) more spikes per burst than was typical, and had shorter than usual interspike intervals. In some of these, the usual $1 \mathrm{msec}$ window starting $1.5 \mathrm{msec}$ after the trough would have included the beginning of the second spike. Thus, for this series of experiments, we used $1 \mathrm{msec}$ windows chosen to be the middle of the interspike interval (midway between the spike peaks) for each cell.

All chemicals and drugs were obtained from Sigma Chemicals (St. Louis, MO) except for apamin (Calbiochem, La Jolla, CA), $\omega$-Aga-IVA (Peptides International, Louisville, KY), scyllatoxin (Peptides International) and mibefradil (the kind gift of Dr. Eric Ertel, Hoffmann-La Roche, Basel, Switzerland).

Data acquisition and analysis. Currents and voltages were low-pass filtered at $10 \mathrm{kHz}$, digitized at $50 \mathrm{kHz}$, and controlled using a Digidata 1200 interface, controlled by pClamp 8 software (Axon Instruments). 
A

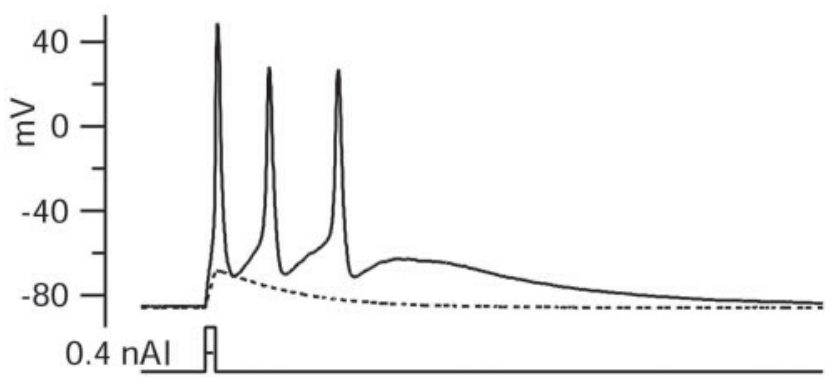

B

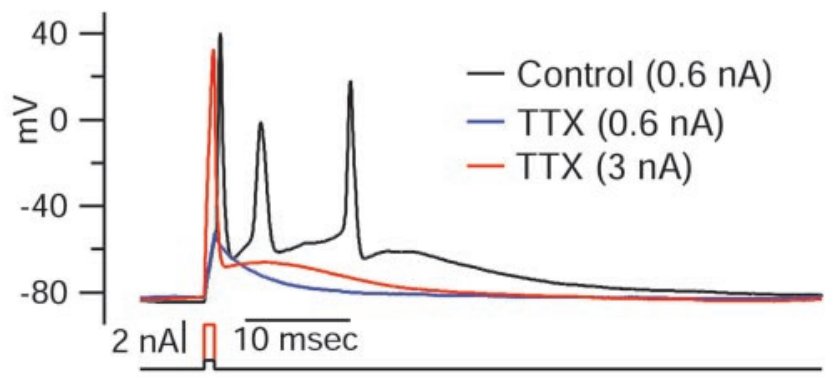

Figure 1. Burst firing in dissociated Purkinje neurons. A, All-or-none burst elicited in response to a brief (1 msec) depolarizing current injection. Dashed trace shows passive response to current injection to just below the voltage threshold. $B$, Effect of $2 \mu \mathrm{m}$ TTX. TTX completely blocked the active response elicited by a moderate suprathreshold current injection (blue), but with a very large $(3 \mathrm{nA})$ current injection for $1 \mathrm{msec}(\mathrm{red})$, the response during the stimulus (passive response to $+30 \mathrm{mV}$, followed by repolarization caused by activation of potassium conductance) was followed by an afterdepolarization.

Analysis was done with Igor Pro (version $\pi$, Wavemetrics, Lake Oswego, OR) using DataAccess (Bruxton, Seattle, WA) to import pClamp files. In some cases the traces shown were additionally digitally filtered with an effective corner frequency of $4 \mathrm{kHz}$. Cell capacitance was measured by integrating the average of $10-15$ current responses to a step from -90 to $-100 \mathrm{mV}$ (with capacitance nulling turned off), filtered at $10 \mathrm{kHz}$, and acquired at $50 \mathrm{kHz}$. Data are presented as mean $\pm \mathrm{SD}$.

\section{Results}

\section{Burst firing of dissociated Purkinje neurons}

With whole-cell recording using internal and external solutions of approximately physiological ionic composition, cells were almost always spontaneously active, firing rhythmically at frequencies of 10-50 Hz (Nam and Hockberger, 1997; Raman and Bean, 1997; Raman et al., 1997). Most cells fired single action potentials at a very regular rate, but some fired spontaneous bursts of action potentials (usually doublets). To record elicited action potentials, spontaneous firing was halted by injecting steady current (generally $30-100 \mathrm{pA}$ ) to hyperpolarize the cell to near $-90 \mathrm{mV}$. Then cells were stimulated by injection of $1 \mathrm{msec}$ current pulses, with increasing magnitude until the cell fired. The current injection was kept short so that no current was injected during the action potentials themselves. The cells responded to current injection by firing bursts of two or more spikes (Song and Narahashi, 1996; Raman and Bean, 1997). Figure $1 A$ shows the response of a Purkinje neuron to subthreshold and just suprathreshold current pulses and illustrates the all-or-none nature of the burst firing. All-or-none burst firing from hyperpolarized potentials was observed in $90 \%$ of dissociated Purkinje neurons $(n=122)$, with two spikes in $62 \%$, three spikes in $21 \%$, and four or more spikes in $7 \%$. The last spike was always followed by an afterdepolarization that failed to progress into a spike. The mean length of the first interspike interval was $5.8 \pm 1.8 \mathrm{msec}$. To quantify interspike voltages, we averaged the voltage over a $1 \mathrm{msec}$ window during the interspike interval, starting $1.5 \mathrm{msec}$ after the post-spike trough. The mean voltage was $-64 \pm 4 \mathrm{mV}(n=90)$ for the first interspike interval, $-65 \pm 4 \mathrm{mV}(n=24)$ for the second interspike interval (in cells that had three or more spikes), and $-70 \pm$ $4 \mathrm{mV}(n=90)$ for the corresponding time interval after the last spike (during the afterdepolarization).

\section{Current-clamp experiments: effects of pharmacological blockers on bursting behavior}

To get an initial indication of the role of different ionic currents in burst firing, we performed current-clamp experiments in which we bath applied blockers of various ion channels to see how they affected the response. When potassium currents were blocked with external TEA at $4 \mathrm{~mm}$, bursts were converted into single spikes followed by a long plateau near $-20 \mathrm{mV}$ (data not shown). This is consistent with previous data showing that the primary voltage-activated and calcium-activated potassium currents in Purkinje neurons are highly sensitive to external TEA (Raman and Bean, 1999; Southan and Robertson, 2000; Martina et al., 2003).

The hyperpolarization-activated cation current, $I_{\mathrm{h}}$, has been implicated in bursting behavior in other neurons (Pape, 1996; Luthi et al., 1998). Purkinje neurons express substantial $I_{\mathrm{h}}$, and it plays a role in regulating tonic firing by maintaining the membrane potential in a range within which the sodium current driving pacemaking is active (Williams et al., 2002). To assess its role in the bursting behavior of Purkinje neurons, we applied $1 \mathrm{mM}$ cesium. Rather than inhibiting burst firing, however, cesium either had no effect on the burst response (two of nine cells) or had the opposite effect, augmenting the afterdepolarization (three of nine cells) or increasing the number of spikes per burst by one (four of nine cells) (data not shown). This slight enhancing effect on burst firing is the opposite of what would be expected if $I_{\mathrm{h}}$ played a major role in driving the burst. It seems most likely that the enhancement of bursting is caused by a small blocking effect of cesium on potassium channels.

Action potentials and bursts were eliminated completely when sodium current was blocked by TTX (Fig. $1 B$ ). To test whether blocking TTX-sensitive sodium channels eliminated all depolarization-activated currents that might contribute to bursting, we increased the magnitude of the $1 \mathrm{msec}$ depolarizing current pulse so that the rapid passive depolarization reached +30 , thus providing a rough simulation of the voltage trajectory of an action potential. During the $1 \mathrm{msec}$ depolarizing stimulus, the initial passive depolarization was followed by a substantial repolarization, presumably caused by activation of potassium conductances. After the $1 \mathrm{msec}$ period of current injection, there was an afterdepolarization. This afterdepolarization had a clear rising phase after the cessation of the depolarizing stimulus, showing that it is caused by the active flow of depolarizing current somehow triggered by the voltage changes during the stimulus. This experiment suggests that currents other than voltage-dependent sodium currents are capable of producing depolarizing currents large enough to contribute substantially to bursting behavior.

Voltage-dependent calcium current is an obvious candidate for the active depolarizing current remaining in TTX; however, although Purkinje neurons are known to possess large voltageactivated calcium currents in the cell body (Regan, 1991), calcium-activated potassium currents are so large and so rapidly activated that under physiological ionic conditions the net current attributable to calcium entry is outward, at least during 
A
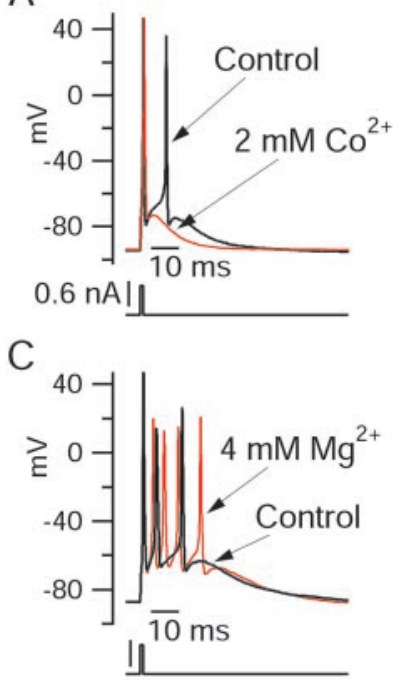

B

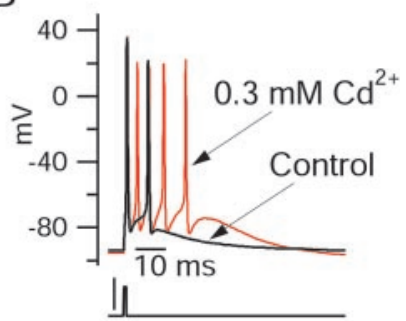

D

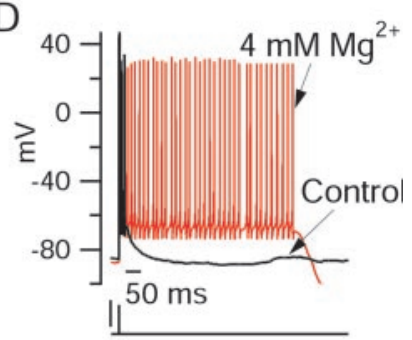

Figure 2. Differential effects of calcium channel blockers on bursting behavior. $A$, Replacing $\mathrm{CaCl}_{2}$ with equimolar $(2 \mathrm{~mm}) \mathrm{CoCl}_{2}$ inhibited bursting. $B$, Blocking calcium current with $0.3 \mathrm{~mm}$ $\mathrm{CdCl}_{2}\left(\mathrm{CaCl}_{2}\right.$ was reduced to $1.7 \mathrm{~mm}$ to keep the total divalent concentration constant) enhanced bursting. C, Replacing $2 \mathrm{~mm} \mathrm{CaCl}$ by $2 \mathrm{~mm} \mathrm{MgCl}$ enhanced bursting. D, In some cases, longlasting plateaus with fast spikes superimposed were triggered when calcium currents were blocked by cadmium or magnesium.

waveforms of action potentials derived from spontaneous pacemaking activity (Raman and Bean, 1999). If this were also true during burst firing, calcium entry would not promote burst firing but would rather oppose it. To examine the role that calcium current may play in burst firing, we examined the effects of cobalt and cadmium, standard inorganic blockers for the calcium current. Surprisingly, these had very different effects on Purkinje cell burst firing (Fig. 2). Cobalt completely inhibited bursting so that stimulation elicited only a single spike $(n=6)$, whereas cadmium enhanced bursting $(n=4)$ and sometimes resulted in longlasting plateau potentials. Either cobalt or cadmium might produce nonspecific effects on channels other than calcium channels. We therefore also tested the effect of replacing calcium with magnesium, which is a normal constituent of the extracellular solution and therefore may be less likely to affect other channels. Replacing calcium with magnesium resulted in enhancement of bursting similar to that seen with cadmium block, sometimes resulting in plateau potentials, and maintained firing for hundreds of milliseconds $(n=7)$.

The results with magnesium replacement suggest that the overall electrical effect of calcium entry is activation of a net outward current, presumably reflecting calcium-activated potassium current that is larger than the inward calcium current activating the potassium current. This result is consistent with the effect of blocking calcium entry in intact Purkinje neurons in cerebellar slices, which results in a depolarizing shift in the upper state of two stable states of activity (Williams et al., 2002).

\section{Sodium current is inhibited by cobalt in Purkinje neurons}

To explore the difference in effect of the different inorganic blockers and to determine the best blocker to use in our later experiments, we performed voltage-clamp experiments examining the effects of the blockers on other channels.

Sodium currents were elicited and isolated by TTX subtraction performed in a background of control $\left(2 \mathrm{Mg}^{2+}, 2 \mathrm{Ca}^{2+}\right)$, magnesium $\left(4 \mathrm{Mg}^{2+}\right)$, cadmium $\left(2 \mathrm{Mg}^{2+}, 1.7 \mathrm{Ca}^{2+}, 0.3 \mathrm{Cd}^{2+}\right)$,

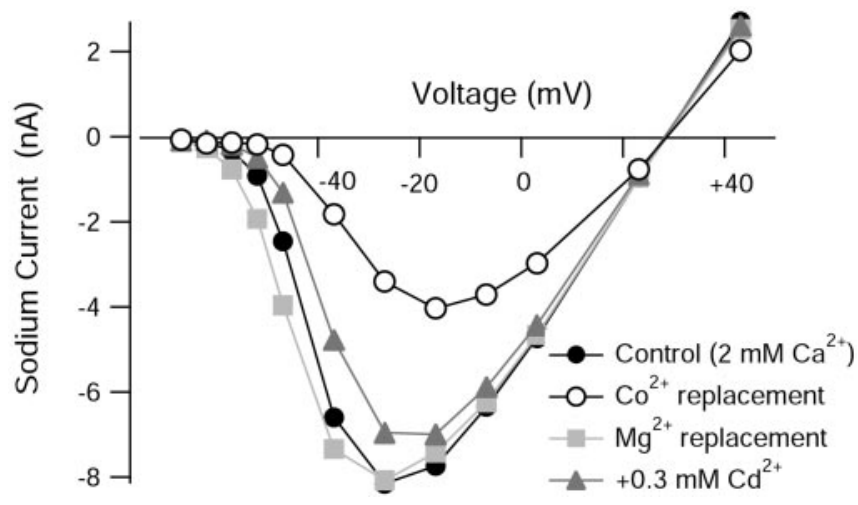

Figure 3. Effects of inorganic calcium channel blockers on the TTX-sensitive sodium current in Purkinje neurons. Plot of peak sodium current versus test potential for a representative cell in which the effects of various calcium channels blockers were assayed. Sodium currents were measured in reduced $\mathrm{NaCl}(50 \mathrm{~mm})$ using TTX subtraction. Holding voltage was $-85 \mathrm{mV}$. For cobalt and magnesium, $2 \mathrm{~mm} \mathrm{CaCl}$ was completely replaced by equimolar $\mathrm{CoCl}_{2}$ or $\mathrm{MgCl}_{2}$. Cadmium was applied as $0.3 \mathrm{~mm} \mathrm{CdCl}_{2}$, with $\mathrm{CaCl}_{2}$ reduced to $1.7 \mathrm{~mm}$ to keep the total divalent concentration constant.

or cobalt $\left(2 \mathrm{Mg}^{2+}, 2 \mathrm{Co}^{2+}\right)$ solutions. Results from a cell in which all three calcium channel blockers were examined are shown in Figure 3. Magnesium replacement of calcium ions had no effect on the magnitude of the sodium current, which reached a peak near $-30 \mathrm{mV}$; there was a slight $(\sim 3 \mathrm{mV})$ change in the voltage dependence of the current elicited by smaller depolarizations, consistent with previous data showing that calcium ions are more effective than magnesium ions in screening surface charge (Hille, 2001b). There was no effect of magnesium replacement on the magnitude of peak sodium current in each of five cells tested. Cadmium $(0.3 \mathrm{~mm})$ produced a modest inhibition of peak sodium current amplitude, with an average reduction by $9 \pm 5 \%$ $(n=5)$. The voltage dependence of activation with cadmium present was slightly shifted in the depolarizing direction. In contrast to magnesium and cadmium substitution for calcium, cobalt substitution had a dramatic inhibitory effect on the magnitude of sodium current, reducing its peak amplitude by an average of $43 \pm 7 \%(n=10)$.

We also checked for possible effects of the inorganic calcium channel blockers on voltage-dependent potassium channels, which could also contribute to differences in the current-clamp behavior of the cells with the different blockers. Applying any of the blockers in physiological solutions reduced total outward current, as expected, because isolated Purkinje neurons possess a prominent component of calcium-activated potassium current (Raman and Bean, 1999). Outward currents elicited by steps from -85 to $0 \mathrm{mV}$ were the same with solutions in which calcium entry was blocked by magnesium, cadmium, or $\omega$-Aga-IVA, consistent with none of these having significant effects on the purely voltage-dependent potassium channels in Purkinje neurons. Currents in cobalt were sometimes slightly smaller, but this effect was not large and not always present.

These experiments suggested that cadmium and magnesium have little effect on sodium and potassium channels, whereas cobalt produces a substantial block of sodium currents and less dramatic effects on potassium currents.

\section{Voltage-clamp experiments: ionic currents contributing to bursting behavior}

The interpretation of the current clamp studies is limited by the complex interactions among multiple voltage-dependent cur- 

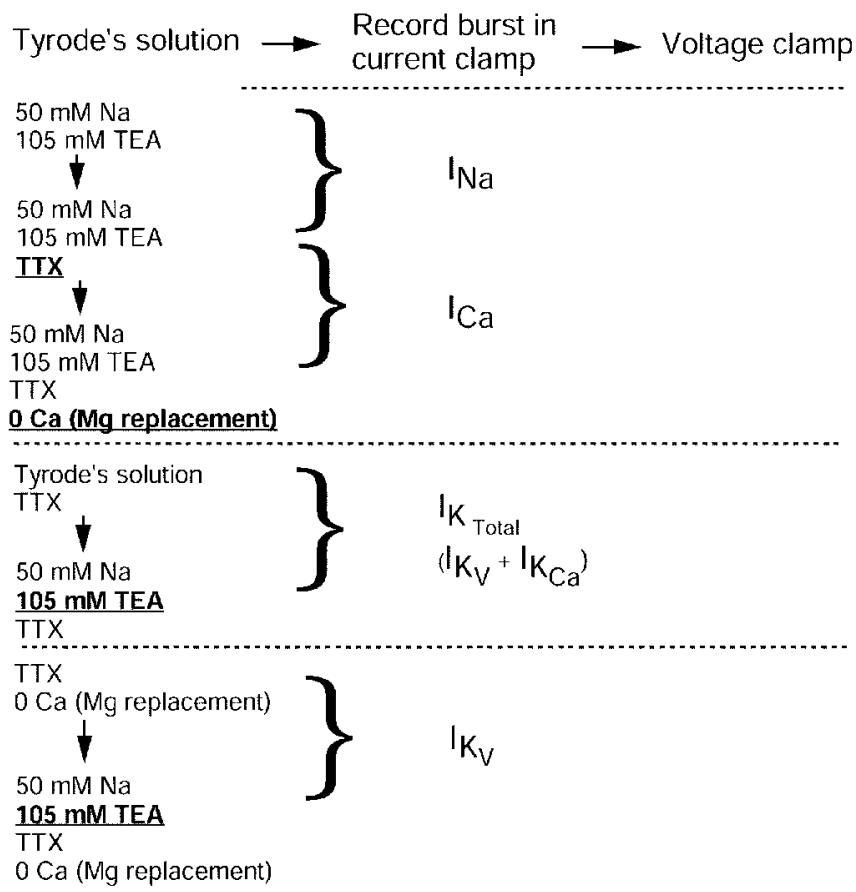

Figure 4. Strategy and solutions for isolating various ionic currents using the action potential clamp. Bursts were first recorded in current clamp. The amplifier was then switched into voltage clamp, and the burst waveform was used as the voltage command. Sodium current was isolated as TTX-sensitive current, with $1 \mu \mathrm{M}$ TTX applied in a solution with reduced (50 mM) sodium to improve voltage control and $105 \mathrm{~mm}$ TEA to block potassium currents. Calcium currents were obtained by subtracting the currents elicited in zero calcium (magnesium replacement) from the currents elicited in full calcium (2 mM), with a background of $105 \mathrm{~mm}$ TEA to block calcium-activated potassium currents. Potassium currents were derived from TEA subtractions with calcium $(\mathrm{KCa}+\mathrm{Kv})$ or without calcium $(\mathrm{Kv})$. Calcium-dependent potassium current was then obtained by subtracting the voltage-dependent potassium current from the total potassium current. Changes in solution are indicated by bold, underlined components.

rents, each of which both determines and is determined by the voltage waveform during the burst. We therefore did a series of experiments using the action potential clamp method, with each cell voltage clamped using its own firing pattern as command voltage (de Haas and Vogel, 1989; Taddese and Bean, 2002). Using a potassium gluconate-based internal solution designed to approximate physiological ionic conditions, initial currentclamp recording was done with a physiological external solution. Cells were hyperpolarized to near $-90 \mathrm{mV}$ with steady hyperpolarizing current and stimulated with $1 \mathrm{msec}$ current injections, and the resulting burst was recorded. Then the amplifier was switched to voltage-clamp mode, compensation for cell capacitance and series resistance was adjusted using $10 \mathrm{mV}$ steps from $-80 \mathrm{mV}$, and the recorded burst was used as the command waveform. Figure 4 shows the sequence of external solution changes that were made to determine the magnitude of various voltagedependent currents flowing during the burst, and Figures 5, 6, and 7 illustrate various aspects of the currents obtained in a typical experiment.

Voltage-dependent sodium current was determined as the current sensitive to 1-3 $\mu \mathrm{M}$ TTX. Because the sodium currents flowing in response to the burst waveform are large and fast, sodium current was measured in solutions containing a reduced concentration of external sodium $(50 \mathrm{~mm})$ to minimize series resistance errors. Sodium was replaced by TEA, which besides being impermeant in sodium channels served to block virtually all of the potassium current, improving the accuracy of the TTX
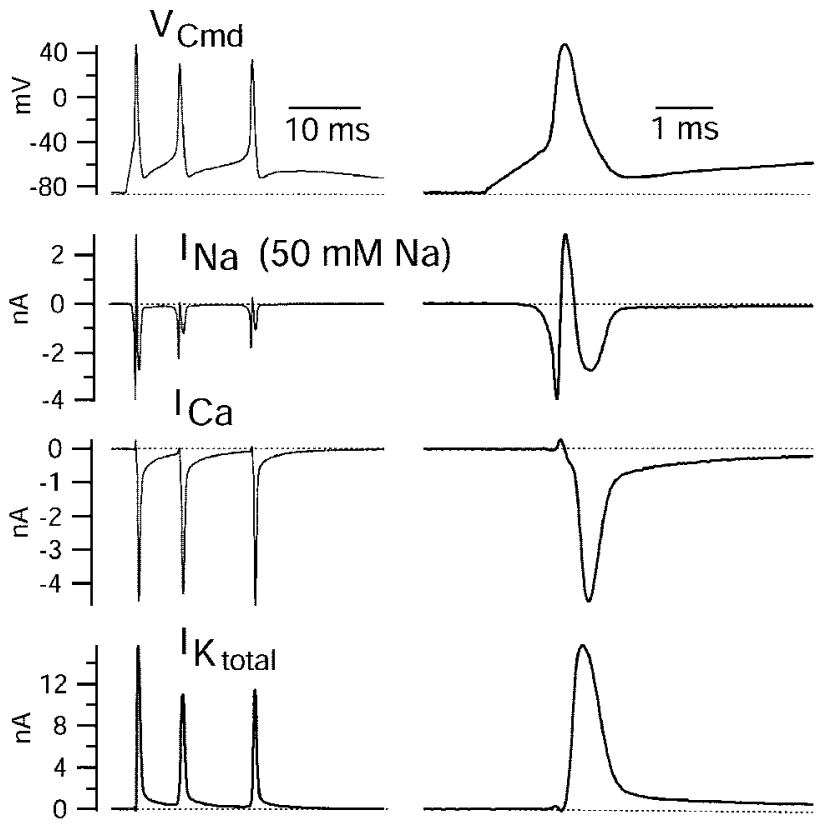

Figure 5. Sodium, calcium, and (total) potassium current elicited by a burst waveform. Right column shows first spike on an expanded time scale. Solution changes are as in Figure 4. Sodium currents were recorded using an external solution containing $50 \mathrm{~mm} \mathrm{NaCl}$ (and $105 \mathrm{~mm}$ TEA). The reversal potential for sodium channel current with this solution is approximately $+28 \mathrm{mV}$, so that sodium channel current is outward at the peaks of the action potentials ( $+44 \mathrm{mV}$ for the first spike), which were recorded in current clamp using $155 \mathrm{~mm}$ sodium.

subtraction. The sodium current obtained by TTX subtraction reaches a peak during the rising phase of the action potentials, as expected, and reverses to become an outward current near the peak of the action potentials. With the reduced external sodium, sodium channel current has a reversal potential of approximately $+28 \mathrm{mV}$ (Fig. 3) and thus is outward at the peak of the action potential $(+44 \mathrm{mV}$ for the first action potential of the burst in Fig. 5). The large magnitude of the outward current $(\sim 3 \mathrm{nA})$ shows that inactivation of the sodium channels is far from complete by the time of the peak. During the second and third spikes of the burst, the inward sodium current during the upstroke is much smaller than during the first spike, presumably reflecting partial inactivation. The outward currents near the peaks are reduced much more, in accordance with the smaller outward driving force associated with the increasingly less positive peaks. For all of the spikes during the burst, there was still a substantial inward current during the repolarizing phase of the action potentials, probably reflecting a combination of current through channels that have not inactivated as well as flow of resurgent current from channels that have inactivated but recover from inactivation partially through the open state (Raman and Bean, 2001).

The additional solution changes to define other currents were performed with solutions that all contained TTX to avoid the necessity of performing subtractions with a background of large sodium currents. The next subtraction involved moving the cell from the solution with TTX and 105 TEA to a solution that was identical except that $\mathrm{Mg}^{2+}$ completely replaced $2 \mathrm{mM} \mathrm{Ca}^{2+}$. The current obtained by this subtraction was inward at all times during the burst, suggesting that this component does not include any substantial calcium-activated potassium current, which should be effectively blocked by $105 \mathrm{~mm}$ external TEA. Calcium current reached a peak during the falling phase of the spike (Fig. 5). Unlike sodium current, the calcium current showed almost no 
A
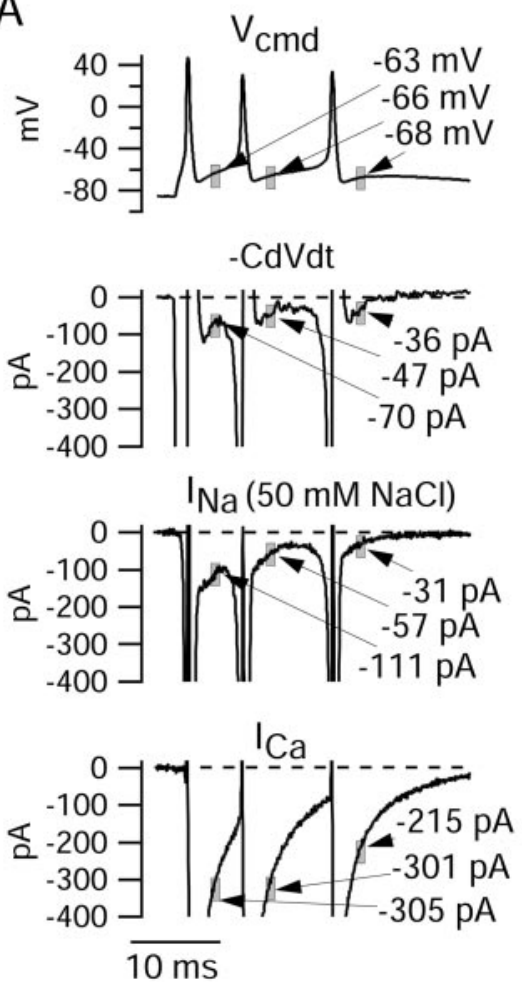
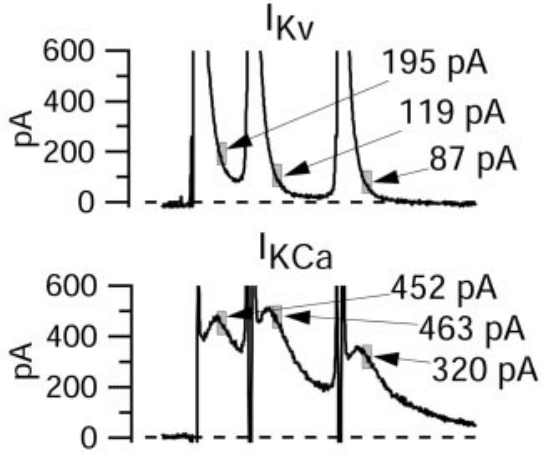

B

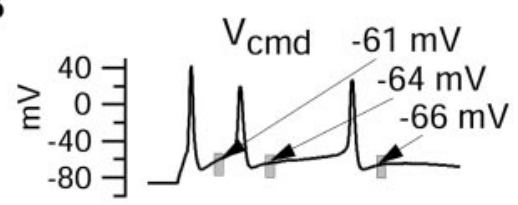

Cesium-sensitive current

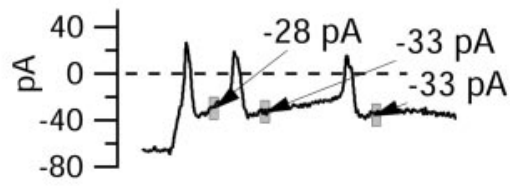

Figure 6. Ionic currents flowing during the interspike intervals of evoked burst. $A$, Solution changes as in Figure 4 . All panels are from the same cell. Values are averaged over a $1 \mathrm{msec}$ window (gray boxes) starting $1.5 \mathrm{msec}$ after the post-spike trough. Sodium currents were recorded in $50 \mathrm{~mm} \mathrm{NaCl}$. Total calcium-activated potassium current contained an apparent transient inward current during the spike (truncated in the figure). This is likely caused by an effect of Ca replacement on the timing of the voltagedependent potassium current during the spike (less effective screening of surface charge by Mg results in a hyperpolarizing shift of voltage dependence of $I_{\mathrm{Kv}}$ and more rapid activation during the spike). $B$, (esium-sensitive current $\left(I_{\mathrm{h}}\right)$ measured in another cell. Top panel shows voltage waveform during the burst in this cell; bottom panel shows current sensitive to $1 \mathrm{~mm} \mathrm{Cs}{ }^{+}$, applied with a background of normal external sodium, with $1 \mu \mathrm{M}$ TTX to block voltage-dependent sodium currents and $4 \mathrm{~mm}$ TEA to block potassium currents. As expected for $I_{h}$, which has a reversal potential near $-30 \mathrm{mV}$ in physiological solutions, the $(\mathrm{s}-$ sensitive current was inward during the interspike intervals but outward during the spikes.

decrement from the first spike to the third spike, suggesting that the calcium channels underlying the current undergo little inactivation during the sequence.

Total potassium current was obtained by blocking the current by substitution of $105 \mathrm{~mm}$ TEA for an equivalent amount of sodium; this was done with a starting solution of normal Tyrode's solution (plus TTX) containing $2 \mathrm{mM} \mathrm{Ca}^{2+}$, so the current obtained by subtraction should include calcium-activated potassium current as well as purely voltage-activated potassium current. There are some components of potassium current that are not blocked by $105 \mathrm{~mm}$ external TEA, but these were $<10 \%$ of the maximum outward current activated by the burst waveform (during the spikes), and there was essentially no outward current remaining during the interspike interval. The total potassium current obtained was very large and reached a peak during the repolarization phase of the first spike $(\sim 16 \mathrm{nA}$ for the burst in the cell of Figs. 5-7) and was only slightly smaller during the repolarizing phase of the second and third spikes.

To separate the total potassium current into calciumactivated and purely voltage-dependent components, a separate subtraction was done with the same substitution of $105 \mathrm{~mm}$ TEA for $\mathrm{Na}^{+}$, but this time using solutions (both before and after the TEA substitution) in which $\mathrm{Mg}^{2+}$ replaced the calcium ions. This defined purely voltage-activated potassium current, and subtracting this from total potassium current then yielded calcium- activated potassium current. Because TEA at $105 \mathrm{~mm}$ effectively blocks SK as well as BK channels (Lang and Ritchie, 1990; Park, 1994), the calcium-activated potassium current obtained in this way should represent an amalgam of current carried by $\mathrm{BK}$ and $\mathrm{SK}$ channels.

Figure $6 A$ shows the currents obtained by these solution changes on an expanded current scale so that the currents flowing during the interspike intervals can be compared. To quantify the contributions of each ionic current in aiding or opposing the interspike depolarization that leads to a subsequent spike, we calculated average current over a $1 \mathrm{msec}$ window during the interspike interval. We chose an interval starting $1.5 \mathrm{msec}$ after the trough of the first spike, so that the $1 \mathrm{msec}$ interval corresponded roughly to the middle of the first interspike interval. We also calculated current in $1 \mathrm{msec}$ intervals starting 1.5 msec after the second and third spike troughs. For an action potential in an isopotential cell, total membrane current is zero, so that net ionic current is equal and opposite to the capacitative current, which can be calculated from the voltage trajectory as $C d V / d t$, where $C$ is cell capacitance and $d V d t$ is the first derivative of voltage (Hodgkin and Huxley, 1952). Thus, we compared the various ionic currents with the net ionic current responsible for generating the depolarization, calculated as $-C d V / d t$ during the interspike interval.

It is apparent from the results in Figure $6 \mathrm{~A}$ that the net ionic current during the interspike interval represents the balance of multiple opposing inward and outward currents that are quite large. Thus, although the net inward current around the midpoint of the first interspike interval is $-70 \mathrm{pA}$, sodium current during the same interval was estimated as $-333 \mathrm{pA}$, calcium current was $-305 \mathrm{pA}$, voltage-activated potassium current was $+195 \mathrm{pA}$, and calcium-activated potassium current was +452 pA. (The estimate of sodium current is on the basis of multiplying the current measured with $50 \mathrm{~mm} \mathrm{Na}^{+}$by a factor of 3; this factor was derived by performing voltage-clamp experiments testing how the magnitude of sodium current varied with sodium concentration when measured at a typical interspike voltage using a burst as command. These calibration experiments were performed in a subset of neurons in which sodium current in full sodium was small enough to be well controlled.) A principal conclusion from the results is that each of the major currents that we examined is quite large relative to the net current required for the interspike depolarization. In this cell, sodium and calcium currents contributed roughly equal amounts of inward current during the first interspike interval. Of the outward potassium currents, calcium-activated potassium current contributed more than twice the current from purely voltage-activated potassium channels.

The sum of sodium current, calcium current, and total potassium current in the first interspike interval of the experiment of Figure $6 A$ was slightly outward (+9 pA). One current not con- 
A

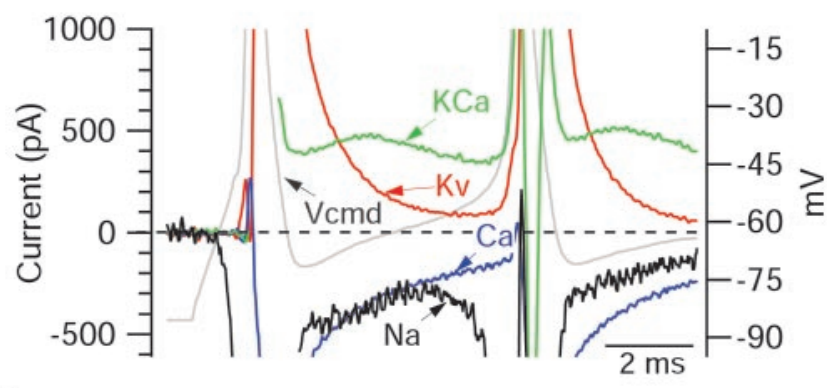

B

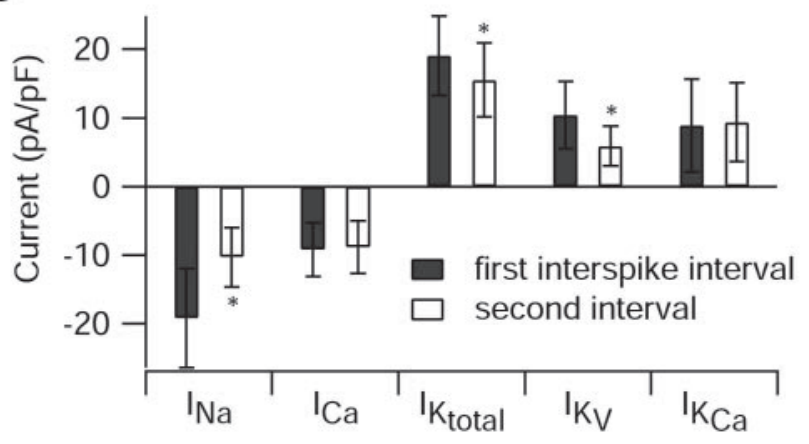

Figure 7. A, lonic currents during the first interspike interval on an expanded current scale to show the differing time course of the various currents during the interspike interval. Same cell as in Figures 5 and 6 . Gray represents voltage during burst waveform (right-hand $y$-axis). Black represents sodium current. Blue represents calcium current. Red represents purely voltageactivated potassium current. Green represents calcium-activated potassium current. $B, \mathrm{Col}$ lected results for magnitude of the various ionic currents during the first and second interspike intervals measured as in Figure 6, averaged over a $1 \mathrm{msec}$ window starting $1.5 \mathrm{msec}$ after the trough and normalized to the capacitance of the cell. Bars show mean \pm SD. ${ }^{*} p<0.001$; paired $t$ test. The data for sodium and calcium currents are from 10 Purkinje neurons, and the data from potassium currents are from 8 of the same neurons in which a full set of solution exchanges was possible.

sidered in the analysis of this cell that may contribute inward current during the interspike interval is $I_{\mathrm{h}} . I_{\mathrm{h}}$ is sensitive to low concentrations of external cesium, providing a convenient means of isolating it in action potential clamp experiments. Because of limitations in the number of solution changes that were feasible, we were not able to do solution changes to determine $I_{\mathrm{h}}$ in the same series in which sodium, calcium, and potassium currents were determined. We therefore did a separate series of experiments to determine the flow of $I_{\mathrm{h}}$ during the burst firing. An example is shown in Figure $6 B . I_{\mathrm{h}}$ was determined as the current sensitive to $1 \mathrm{mM} \mathrm{Cs}^{+}$, applied in a background of normal external sodium (and with TTX to block voltage-dependent sodium currents and 4 TEA to block potassium currents). As expected for $I_{\mathrm{h}}$, which has a reversal potential near $-30 \mathrm{mV}$ in physiological solutions, the Cs-sensitive current was inward during the interspike intervals and outward during the spikes. Relative to sodium, calcium, and potassium currents, however, the magnitude of $I_{\mathrm{h}}$ between spikes was consistently small, averaging $-17 \pm 13$ $\mathrm{pA}(n=10)$ during the first interspike interval.

Figure $7 A$ shows the sodium, calcium, and potassium currents during the burst superimposed on an expanded scale so that their timing, relative to the command potential and to each other, can be seen more clearly. To facilitate comparison of the relative magnitudes of the currents, the sodium current is shown scaled by a factor of 3 from that measured in $50 \mathrm{mM} \mathrm{Na}^{+}$, which provides an estimate of the sodium current that would flow with full external sodium at relatively small depolarizations such as the initial up- stroke and the interspike intervals. During the interspike interval in this cell, sodium current and calcium current are of similar magnitude and also have similar time courses, and both contribute a large inward current during the repolarization of the action potential followed by an inward current of several hundred picoamperes that decays slowly during the interspike interval but never reaches zero. During the interspike interval, the purely voltage-dependent potassium current is still extremely large $(>1$ $\mathrm{nA}$ ) at the time of maximal hyperpolarization but decays with faster kinetics than the opposing sodium and calcium currents. The calcium-activated potassium current has a very different time course, increasing during the first half of the interspike interval (presumably in response to increasing submembrane calcium) and then declining slightly. During the first third of the first interspike interval, voltage-activated potassium current is larger than calcium-activated potassium current but then decays rapidly so that calcium-activated potassium current is the dominant outward current in the later parts of the interspike interval. The net current at each point during the interspike interval clearly represents the sum of multiple large currents that each are dynamically changing.

Figure $7 B$ illustrates collected results on the magnitude of various currents during interspike intervals. To minimize errors caused by poor voltage clamp, sodium currents were also elicited from a series of voltage steps, and cells showing evidence of being poorly controlled were not used for further analysis. In the collected results, sodium current during the first interspike interval was the dominant inward current, approximately twice as large as calcium current.

On average, the total outward potassium current near the middle of the first interspike interval was composed of roughly equal proportions of calcium-dependent and purely voltageactivated components, but because voltage-dependent potassium current decays rapidly, calcium-activated potassium current dominates later in the interspike interval.

What causes the burst to terminate? We addressed this question by examining differences in the various currents between the first and second intervals. In fact, 8 of the 10 cells included in the analysis of Figure $7 B$ fired only two spikes during the burst, so the second interval was between the second spike and the afterdepolarization. For these eight cells, changes in currents from after the first spike to after the second spike are thus correlated with the difference between firing or failing to fire a subsequent spike. In principle, termination of the burst could be caused by either a reduction in inward current or an enhancement of outward current. The results show that the major difference between currents after the second spike compared with those after the first is a reduction in the TTX-sensitive sodium current. In the cells with two spikes per burst, the sodium current decreased by nearly a factor of 2 from the first interspike interval to the second interval (ratio of current in the second interval relative to that in the first, $0.54 \pm 0.10$; mean $\pm \mathrm{SD} ; n=8)$. In contrast, there was little change in calcium current $(0.96 \pm 0.10 ; n=8)$. Total potassium current declined slightly $(0.81 \pm 0.11 ; n=6)$ after the second spike, because of a substantial reduction in voltage-activated potassium current $(0.56 \pm 0.09 ; n=6)$. This likely reflects a fastinactivating component of potassium current seen with activation by voltage steps (Wang et al., 1991; Raman and Bean, 1999; Sacco and Tempia, 2002). On average, there was a slight increase in calcium-activated potassium current from the first to second interspike interval, but the change was highly variable from cell to cell $(1.14 \pm 0.36 ; n=6)$.

These results suggest that a decrease in interspike sodium cur- 
rent after the second spike is a major factor in limiting burst length, at least for bursts consisting of two spikes. The sodium current during the interspike interval is probably a combination of steady-state persistent sodium current and dynamic resurgent current (Raman and Bean, 1997; Raman et al., 1997; Kay et al., 1998). The decline of interspike sodium current from the first to the second interval can be understood at least in part from the properties of resurgent sodium current. Resurgent current appears to depend on entry of channels into an unusual inactivated state, from which they recover through the open state when the membrane is repolarized (Raman and Bean, 2001). Channels enter this unusual inactivated state most effectively during large, short depolarizations, whereas maintained depolarizations favor entry into conventional inactivated states, from which recovery occurs without resurgent current. Thus, resurgent current would be predicted to decline after maintained small depolarizations, like those during the interspike intervals of a burst. In principle, steady-state persistent sodium current would not be expected to change from one interval to the next, because it is not subject to fast inactivation. It is possible, however, that persistent sodium current (as well as resurgent current) could be reduced somewhat by a process of slow inactivation, as in subthalamic nucleus neurons (Do and Bean, 2003) (see also Fleidervish et al., 1996). It is possible that slow inactivation might be significant after just a few spikes (Taddese and Bean, 2002).

\section{Calcium current: contribution of different channel types}

The voltage-activated calcium current in the cell bodies of Purkinje neurons is known to have major contributions from T-type and P-type calcium channels, along with minor contributions from L-type and N-type calcium channels (Kaneda et al., 1990; Regan, 1991; Mintz et al., 1992b; Usowicz et al., 1992; McDonough and Bean, 1998). Because T-type and P-type channels have considerably different voltage dependence and kinetics, they are likely to have different patterns of activation during bursts. We did experiments to determine the distinct roles of the P-type and T-type channels during bursting. We used $\omega$-Aga-IVA (Mintz et al., 1992a,b) to isolate the calcium current carried by P-type calcium channels and mibefradil (McDonough and Bean, 1998) to determine the contribution of T-type calcium channels. $\omega$-AgaIVA is highly selective for P-type over T-type channels (Mintz et al., 1992b; Mintz and Bean, 1993). Mibefradil is a much more potent blocker of T-type channels than P-type channels under the same conditions, but depending on the holding potential there can be some block of P-type channels at concentrations necessary to produce complete block of T-type channels $(\mathrm{McD}$-nough and Bean, 1998). We therefore applied $\omega$-Aga-IVA first, so that mibefradil could be applied at a relatively high concentration without the possibility that the mibefradil-sensitive component would include P-type current.

Figure $8 \mathrm{~A}$ shows the flow of $\mathrm{P}$-type and T-type current during a three-spike burst. The two types of calcium current had considerably different time courses. Both reached a peak during the falling phase, T-type a bit later ( $0.88 \mathrm{msec}$ after the spike peak) than P-type ( 0.44 msec after the peak); however, the most striking difference was the much slower decay of T-type current, which remained substantial throughout the interspike interval. Figure $8 \mathrm{~B}$ shows collected results comparing T-type and P-type current during bursts. On average, the T-type current during the first interspike interval was fivefold higher $(-8.0 \pm 6.2 \mathrm{pA} / \mathrm{pF} ; n=$ $24)$ than P-type current $(-1.6 \pm 2.8 \mathrm{pA} / \mathrm{pF} ; n=24)$. The sum of P-type current density and T-type current density was only slightly smaller $(95 \pm 7 \%)$ than the total calcium current density
A
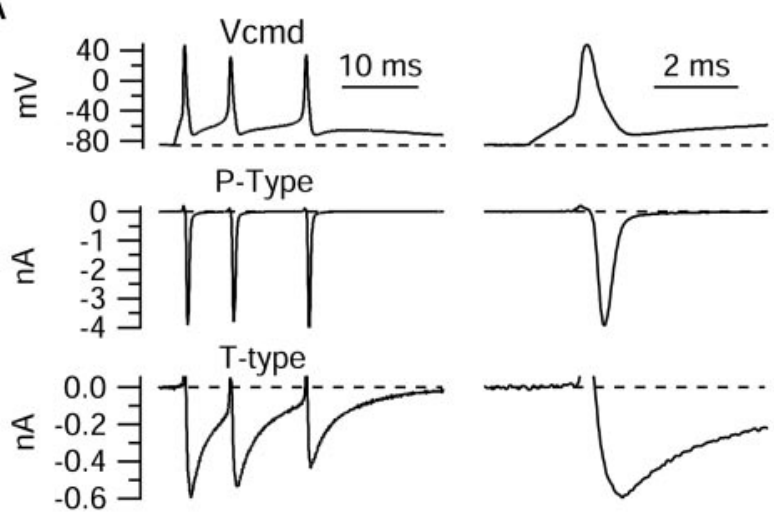

B

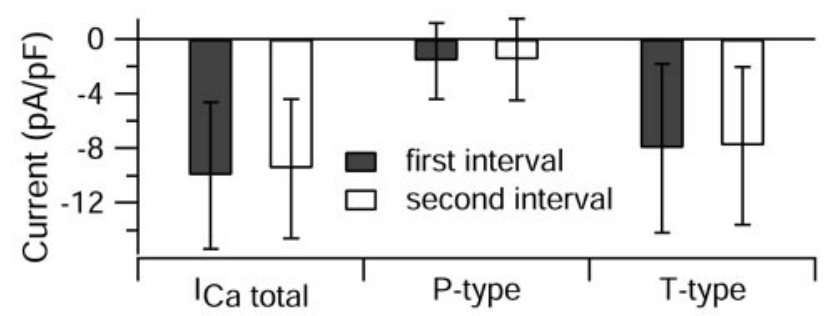

Figure 8. P-type and T-type calcium currents during elicited bursts. A, Time course of P-type and T-type calcium channel currents during a burst. P-type current was defined as current (carried by $2 \mathrm{~mm}$ calcium) blocked by $200 \mathrm{~nm} \omega$-Aga-IVA, applied in an external solution of 50 $\mathrm{mm} \mathrm{NaCl}, 105 \mathrm{TEACl}, 4 \mathrm{~mm} \mathrm{KCl}, 2 \mathrm{~mm} \mathrm{CaCl}, 2 \mathrm{~mm} \mathrm{MgCl}$, 10 mm HEPES, pH 7.4 with NaOH, with $1 \mu \mathrm{m}$ TTX. T-type current was defined as the current blocked by $10 \mu \mathrm{m}$ mibefradil added in the continuous presence of $\omega$-Aga-IVA. B, Collected results for magnitude of total calcium current, P-type calcium current, and T-type calcium current. Currents were averaged over a $1 \mathrm{msec}$ window starting $1.5 \mathrm{msec}$ after the trough and normalized to the capacitance of the cell. Bars show mean \pm SD. Total calcium current was determined by $\mathrm{Mg}^{2+}$ replacement of calcium; then, in the same cells, P-type current and T-type current were determined as in $A$. The sum of P-type and T-type currents was $95 \pm 7 \%$ of the total calcium current determined by $\mathrm{Mg}^{2+}$ replacement.

determined in the same cells by magnesium replacement for calcium in the presence of external TEA to block calcium-activated potassium current. This is consistent with minimal contributions of calcium channels other than P-type and T-type channels.

Surprisingly, T-type current did not appear to inactivate very much during the burst. There was very little change from the first interspike interval to the second interval (ratio of current in the second interval relative to that in the first was $1.00 \pm 0.16 ; n=$ 24). Lack of dramatic inactivation is also evidenced by the sizeable T-type current elicited by the third spike in the burst in Figure $8 A$; this was reduced only $\sim 25 \%$ compared with the first spike, and some of the reduction is likely attributable to the smaller amplitude of the third spike.

\section{Spontaneous bursts in Purkinje neurons}

The results so far concern bursts elicited by injection of short current pulses in neurons with spontaneous firing that was silenced by hyperpolarization. Burst firing can also occur spontaneously in dissociated Purkinje neurons. In cell-attached recordings of spontaneous activity (taken before breaking through into whole-cell mode), many cells (41 of 68) showed action currents composed of doublets or triplets, sometimes occurring regularly and rhythmically and sometimes irregularly, interspersed with singlets. Figure $9 A$ shows an extracellular recording from a cell that spontaneously fired doublets and triplets. The structure of spontaneous bursts seemed generally quite similar to that of elic- 


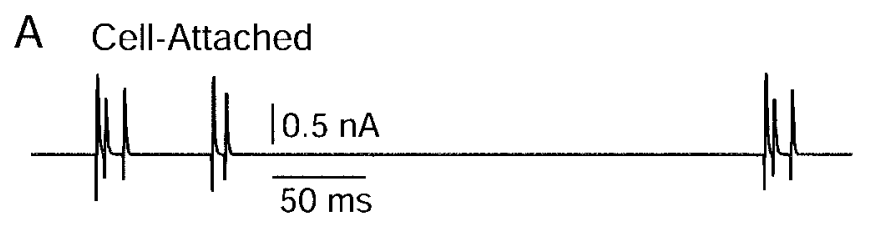

B Cell-Attached
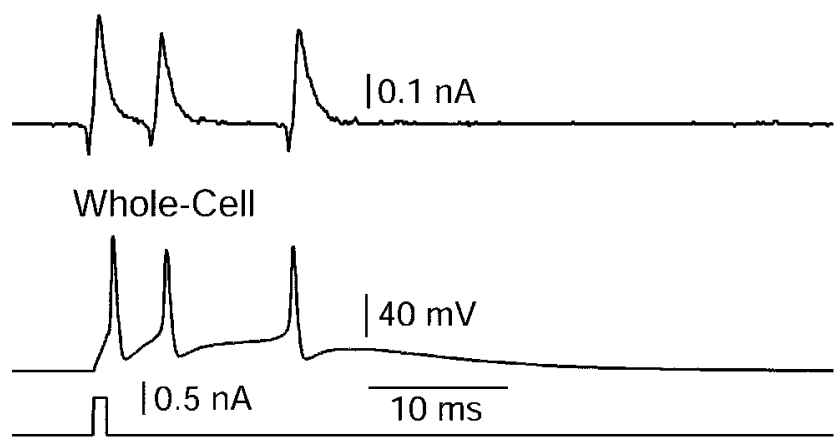

Figure 9. Spontaneous bursts recorded extracellularly in cell-attached mode. A, Spontaneous two and three spike bursts recorded extracellularly in cell-attached mode from a dissociated Purkinje neuron. B, A spontaneous burst recorded in cell-attached mode extracellularly (top panel) and an elicited burst recorded from the same cell in whole-cell current-clamp mode after breaking through the membrane. Spontaneous and triggered bursts showed very similar time courses and number of spikes per burst. In cell-attached recordings, pipettes contained standard intracellular solution with high potassium; large upward currents reflect ionic current flowing from the pipette into the cell when potassium channels in the patch are open.

ited bursts. Figure $9 B$ compares a spontaneous burst recorded in a cell before breaking through with an elicited burst recorded intracellularly after breaking through; in both cases, the burst consisted of a triplet, with similar timing of the three action potentials in each case. This suggests that the elicited bursts may capture physiological behavior of the cells reasonably well.

In whole-cell recordings, spontaneous firing in $\sim 20 \%$ of the cells occurred as bursts, usually doublets or triplets. Most likely the lower fraction of cells showing spontaneous bursting in whole-cell mode compared with cell-attached mode reflects the influence of an additional small depolarizing current caused by leak around the seal in whole-cell mode; in cells that spontaneously fired single spikes in a rhythmic manner, application of a small, steady hyperpolarizing current (typically 5-15 pA) converted rhythmic single spike firing to rhythmic burst firing. We examined the ionic currents flowing during this spontaneous bursting behavior. We were particularly interested in the role of T-type calcium current because the spontaneous bursts developed from less hyperpolarized voltages (typically -80 to -70 $\mathrm{mV}$ ) than those studied in the first series of experiments (typically elicited from near $-90 \mathrm{mV}$ ).

Figure 10 shows a sample trace of a Purkinje neuron the spontaneous firing of which in whole-cell mode occurred in bursts, along with traces of the various ionic currents flowing throughout the burst. The interspike intervals within spontaneous bursts were longer $(11.0 \pm 2.3 \mathrm{msec})$ than those for elicited bursts $(5.8 \pm 1.8 \mathrm{msec})$; therefore, the window for quantifying interspike currents and voltages was chosen as an interval $1.4 \mathrm{msec}$ wide, starting $4.8 \mathrm{msec}$ after the post-spike trough, near the middle of a typical interspike interval. The mean voltage for the first interspike interval was $-65 \pm 4 \mathrm{mV}(n=19)$. The mean current values (Fig. 11) show that the individual current components near the middle of the interspike intervals are all smaller in mag-

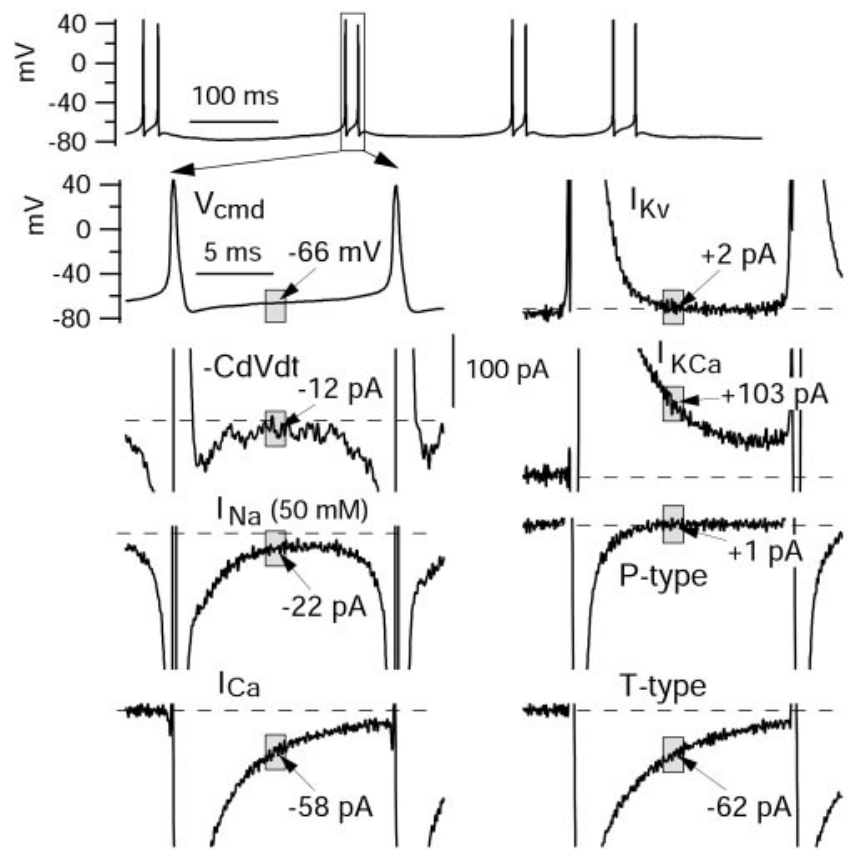

Figure 10. Ionic currents flowing during the interspike intervals in spontaneous bursts. Indicated values are averaged over a $1.4 \mathrm{msec}$ window (gray box) starting $4.8 \mathrm{msec}$ after the post-spike trough. All currents, including P-type and T-type calcium currents, were recorded in a single cell. Sodium currents are as recorded in reduced $\mathrm{NaCl}$.

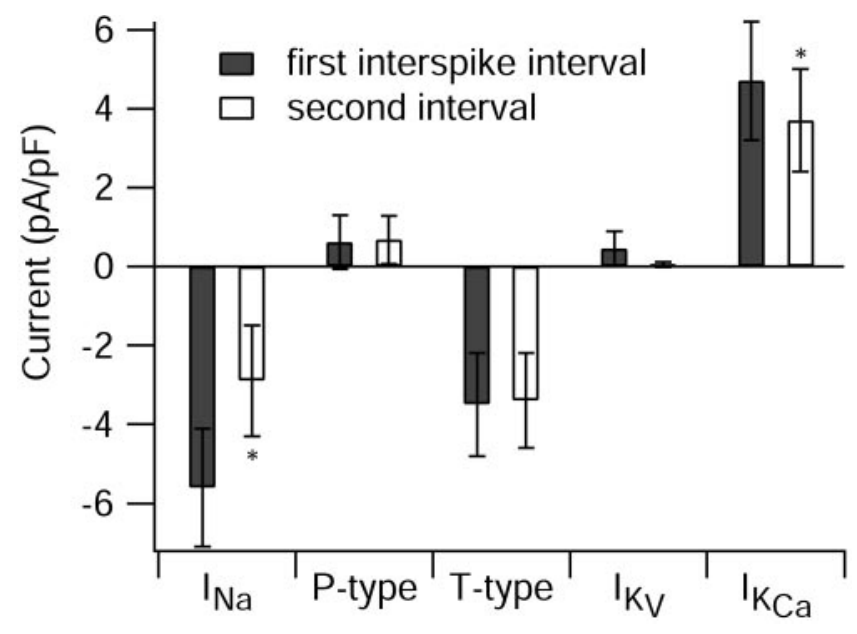

Figure 11. Ionic currents flowing during the first and second intervals of spontaneous bursts of Purkinje neurons. Sodium current densities shown were scaled up by a factor of 3 from those measured in $50 \mathrm{~mm}$ sodium. Values are averaged over a $1.4 \mathrm{msec}$ window starting $4.8 \mathrm{msec}$ after the post-spike trough. For sodium current and potassium currents, $n=5$ cells. For P-type and T-type currents, $n=18$ cells. ${ }^{*} p<0.01$; paired $t$ test.

nitude compared with those observed for the elicited bursts (Fig. $7 B)$, but their relative contributions are fairly similar. Thus, sodium current and T-type calcium current were the dominant inward currents, and $I_{\mathrm{h}}$ was small $(0.3 \pm 0.3 \mathrm{pA} / \mathrm{pF} ; n=6)$, making up $<3 \%$ of the total inward current. This suggests that the basic bursting mechanism is the same as for elicited bursts. The most notable difference was that calcium-activated potassium current carried virtually all total potassium current during the middle of the interspike interval during spontaneous bursts. The large reduction of interspike sodium current appears to play an important role in the termination of spontaneous bursts just as it does for elicited bursts. 
A

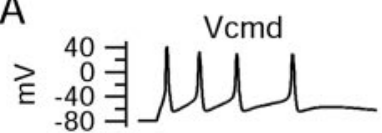

BK current

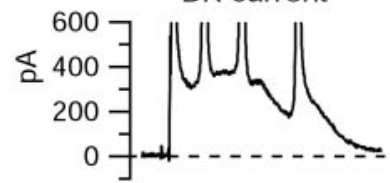

B

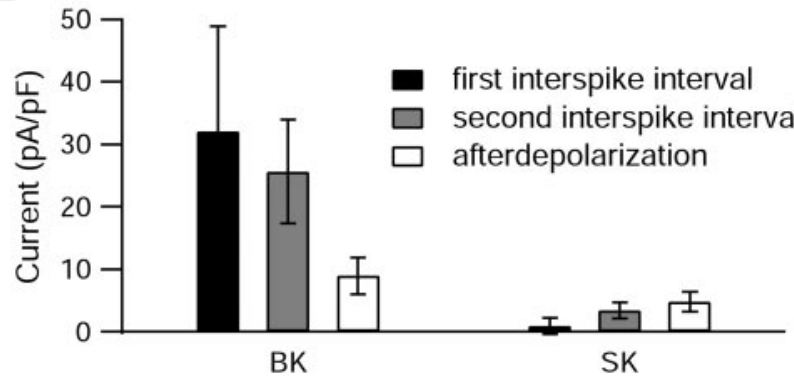

Figure 12. Large-conductance and small-conductance calcium-activated potassium currents flowing during elicited bursts. $A$, BK current (left) was obtained as the current sensitive to $150 \mathrm{~nm}$ iberiotoxin. SK current (right) was obtained as the current sensitive to $30 \mathrm{~nm}$ scyllatoxin. $B$, Collected results for the size of BK and SK currents during bursts of three or more spikes ( $n=$ 7). BK current was obtained as current sensitive to 100-150 nm iberiotoxin, and SK current was obtained as current sensitive to $30 \mathrm{~nm}$ scyllatoxin (4 cells) or $200 \mathrm{~nm}$ apamin (3 cells). For each burst, values for the first and second interspike intervals were averaged over a $1 \mathrm{msec}$ window in the middle of the interspike interval (and normalized to the capacitance of the cell). Values for the afterdepolarization (ADP) were averaged over a 1 msec time window around the peak of the $A D P$. Error bars represent mean $\pm S D$.

\section{Calcium-activated potassium currents: contribution of BK and SK channels}

Because calcium-activated potassium current makes up such a large portion of the total outward current during the interspike intervals of bursts, we were interested in separating this current into its BK and SK components. Both types of calcium-activated potassium channels are known to be present in Purkinje neurons (Jacquin and Gruol, 1999; Cingolani et al., 2002; Womack and Khodakhah, 2002a, 2003; Edgerton and Reinhart 2003). We therefore did a series of experiments in which selective blockers were used to isolate components of potassium current through BK and SK channels. Figure $12 \mathrm{~A}$ shows examples of the BK (left) and SK (right) currents flowing during elicited bursts. BK current was isolated by its sensitivity to $150 \mathrm{~nm}$ iberiotoxin and SK current by its sensitivity to $30 \mathrm{~nm}$ scyllatoxin. BK current was large during the falling phase of the spikes; it declined rapidly late in the spike but had a substantial plateau $(300-400 \mathrm{pA})$ in the first two interspike intervals. BK current became progressively smaller in the third interspike interval and during the afterdepolarization that followed the last spike. In contrast, SK current was small during the spikes, but gradually increased with each successive interspike interval and reached a maximum (at $\sim 55 \mathrm{pA}$ in this cell) during the afterdepolarization. In other cells, similar results for SK current were obtained using $200 \mathrm{~nm}$ apamin. Figure $12 \mathrm{~B}$, which shows the mean values across seven cells that had three or more spikes per burst, further illustrates the different patterns of BK and SK activation during bursts. On average, BK current decreased by $73 \%$ from the first interspike interval to the afterdepolarization (from $523 \pm 279$ to $140 \pm 41 \mathrm{pA} ; p=0.008$; paired $t$ test). SK current, on the other hand, increased $381 \%$ from the first interval to the afterdepolarization (from $16 \pm 21$ to $77 \pm 29$

$\mathrm{pA} ; p=0.002)$. Thus, BK current progressively decreases during the burst, whereas SK current progressively increases.

The magnitude of BK current during the interspike interval (and of total calcium-activated potassium current, dominated by BK current) showed wide variability from cell to cell. The variability in interspike BK current is probably mainly attributable to the steep voltage dependence of the conductance-voltage curve for BK current; the interspike BK current essentially represents incomplete deactivation of the current activated during the spike and corresponds to the foot of the activation curve, which has an exponential dependence on voltage and the position of which depends strongly on instantaneous intracellular calcium. Typical interspike voltages near $-65 \mathrm{mV}$ are near the foot of the activation curve for calcium concentrations near $30 \mu \mathrm{M}$ (Womack and Khodakhah, 2002a), a plausible value while calcium currents are flowing. The magnitude of interspike BK current for the seven cells in Figure $12 \mathrm{~B}$ is almost threefold larger than the total interspike calcium-activated potassium current for the eight cells in Figure $7 B$. The main reason for the difference is probably that the cells used for the experiments in Figure $12 B$ had significantly more depolarized interspike intervals $(-56 \pm 3 \mathrm{mV})$ than those in Figure $7 B(-66 \pm 4 \mathrm{mV})$. The intrinsic density of BK channels was similar in the two sets of cells, because the magnitude of calcium-activated potassium current activated by steps to -17 $\mathrm{mV}$ (dominated by BK current) for the cells in Figure $7 B(287 \pm$ $74 \mathrm{pA}$ ) was quite similar to the magnitude of BK current elicited by steps to $-15 \mathrm{mV}$ for the cells in Figure $12 \mathrm{~B}(255 \pm 67 \mathrm{pA})$.

The decline of BK current during the burst probably reflects the fact that successive interspike intervals are progressively less depolarized. In addition, the decline of BK current may be caused in part by intrinsic inactivation of these channels, as reported previously in Purkinje neurons (Raman and Bean, 1999; Khaliq et al., 2003). When we examined the time course of BK current evoked by $50 \mathrm{msec}$ steps to $-15 \mathrm{mV}$, the degree of inactivation during the step varied dramatically from cell to cell, from very little (9\% decay) to nearly complete ( $99 \%$ decay; data not shown). On average, BK current decayed by $63 \pm 35 \%$ during 50 msec at $-15 \mathrm{mV}(n=9)$. The wide cell-to-cell variability in inactivation agrees with previous observations by Khaliq and colleagues (2003).

The activation of both BK and SK currents during burst waveforms motivated us to look at the effects of BK and SK blockers on bursts in current clamp. Figure 13 shows the effects of iberiotoxin and apamin on bursts elicited by short current injections. Despite the large size of the BK currents during bursts, iberiotoxin generally had relatively subtle effects (Fig. 13A). At $100 \mathrm{~nm}$, iberiotoxin increased the number of spikes from two to three in each of four cells tested. Consistent with the large BK current during the first interspike interval, iberiotoxin substantially decreased the length of the first interspike interval, from $9.9 \pm 3.4$ to $3.8 \pm 1.0$ msec ( $p=0.04$; paired $t$ test). Although increasing bursts from two to three spikes, iberiotoxin on average had no effect on the burst duration ( $9.9 \pm 3.4$ vs $10.6 \pm 5.8 \mathrm{msec} ; p=0.84$; measured from peak of first spike to peak of last spike), reflecting the reduction in interspike intervals.

Blocking SK current by $200 \mathrm{~nm}$ apamin $(n=8)$ or $30 \mathrm{~nm}$ scyllatoxin $(n=3)$ had more dramatic effects, increasing the number of spikes in the burst from an average of $2.5 \pm 0.9$ in control to $11.8 \pm 11.9$ after block of SK channels $(n=11)$ and increasing the burst duration from $10 \pm 8$ to $109 \pm 115 \mathrm{msec}$. The large variability in burst length in the presence of SK blockers reflects long-lasting plateau potentials that were often produced and had variable lengths from trial to trial. Unlike block of BK 
A
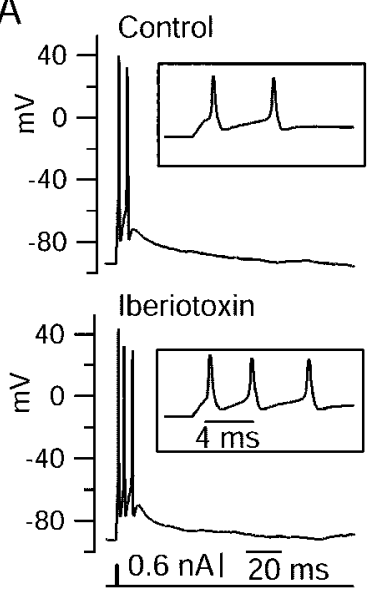

B
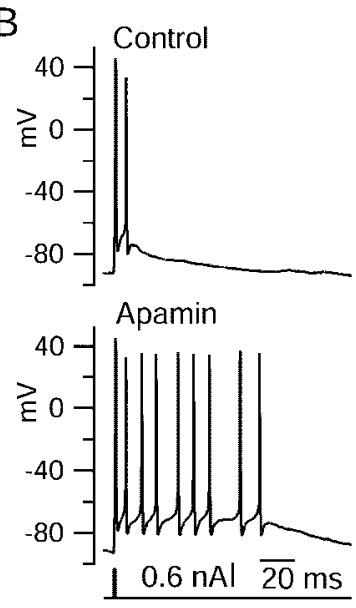

Figure 13. Effects of BK and SK block on elicited bursts. $A$, The BK blocker iberiotoxin (100 nм) shortened the initial interspike interval and increased the burst from two spikes to three. Inset, Expanded time scale. $B$, The SK blocker apamin (200 nm) increased the burst from two spikes to nine spikes.

channels, block of SK channels had no effect on the length of the first interspike interval $(5.5 \pm 2.1$ vs $5.6 \pm 1.6 \mathrm{msec})$. This is consistent with the small SK current during the first interspike interval. In nine cells, we applied iberiotoxin after SK block. Just as when it was applied alone, iberiotoxin decreased the first interspike interval (by $39 \%$; from $5.4 \pm 1.6$ to $3.3 \pm 0.9 \mathrm{msec} ; p<$ 0.001 ). Additional block of BK current did not obviously have a further effect on burst length, but because burst length in the presence of SK blockers alone was highly variable from trial to trial, it was not feasible to quantify possible further effects of iberiotoxin.

These results suggest distinct roles for BK and SK channels in bursting behavior, with BK channels strongly influencing spike timing during the burst and SK channels playing a more major role in burst termination. It was surprising to see larger effects on burst length of blocking SK current than of blocking BK current, because BK current was much larger than SK current throughout the burst. BK current declined during the burst, probably reflecting partial inactivation of $\mathrm{BK}$ current that has been noted previously (Raman and Bean, 1999; Khaliq et al., 2003), whereas SK current increased during the burst; even so, during the afterdepolarization at the end of the burst, BK current was still on average about twice as big as SK current (Fig. 12B). The more limited effects of blocking BK current compared with SK current may reflect the very different sensitivities of SK current and BK current to increases in spike number and frequency. SK current may increase steeply with spike frequency and spike number caused by buildup of submembrane calcium and thus provide a very powerful negative feedback element on burst length. In contrast, BK current actually declines during bursts and evidently provides no such powerful feedback element when bursts are enhanced by block of SK current.

Neither iberiotoxin nor apamin or scyllatoxin had significant effects on the width of the first spike or on the most negative voltage reached after the first spike. Spike width was $0.41 \pm 0.06$ msec before $100 \mathrm{~nm}$ iberiotoxin and $0.40 \pm 0.06 \mathrm{msec}$ after ( $p=$ 0.39 ; paired $t$ test; $n=4$ ), and the afterhyperpolarization was $-66.1 \pm 2.8 \mathrm{mV}$ before and $-65.5 \pm 2.2 \mathrm{mV}$ after $(p=0.12$; paired $t$ test). With application of $200 \mathrm{~nm}$ apamin or $30 \mathrm{~nm}$ scyllatoxin, spike width was $0.43 \pm 0.09 \mathrm{msec}$ before toxin and $0.44 \pm$ $0.08 \mathrm{msec}$ after, and the afterhyperpolarization was $-65.3 \pm 4.3$

$\mathrm{mV}$ before and $-65.1 \pm 4.3 \mathrm{mV}$ after $(n=11)$. The lack of effect on spike shape of blocking SK current agrees with previous results examining action potentials during spontaneous firing of Purkinje neurons studied in cerebellar slices (Edgerton and Reinhart, 2003; Womack and Khodakhah, 2003) and is consistent with the lack of substantial activation of SK current during the first spike. Given the large amount of BK current activated during the spike (Womack and Khodakhah, 2002a), it might be expected that blocking this current would increase spike width or reduce the afterhyperpolarization. Indeed, a reduction of the afterhyperpolarization was seen with application of iberiotoxin for spontaneous action potentials studied in Purkinje neurons in slices (Womack and Khodakhah, 2002a; Edgerton and Reinhart, 2003). It is not clear why this effect is not seen for elicited action potentials in dissociated cells. Perhaps it is because although BK current during the spike is large, purely voltage-activated potassium current is even larger (Fig. 7A).

The increased burst length seen with block of SK currents fits well with an increased propensity to bursting seen when blocking SK current during spontaneous firing of Purkinje neurons in slices, where there is conversion of regular tonic firing to periods of bursts interspersed with silent periods (Edgerton and Reinhart, 2003; Womack and Khodakhah, 2003).

\section{Discussion}

Our results show that the post-spike inward currents driving burst firing in Purkinje neurons are carried primarily by TTXsensitive sodium channels and T-type calcium channels, with very little contribution of $I_{\mathrm{h}}(\sim 3 \%$ of the total inward current). The net inward current between spikes represents the balance of contributions from multiple conductances, with the currents from sodium channels and calcium channels opposed by large calcium-activated and purely voltage-activated potassium currents. In the middle of the interspike interval, each of these currents has an absolute magnitude of many times the net inward current, so that relatively small changes in any of them could affect the number and timing of spikes in a burst. It is striking that SK current is relatively small but nevertheless exerts powerful control over the duration of bursting. Transmitter control of SK current has been described in many types of neurons (Nicoll, 1988), and resurgent sodium current may be regulated by phosphorylation (Grieco et al., 2002), raising the possibility of transmitter modulation of Purkinje neuron bursting. Tonic firing frequency can be modulated by synaptically released nitric oxide (Smith and Otis, 2002), and the ionic conductances underlying this modulation, which are not yet known, could well affect burst firing also.

In cells firing two-spike bursts, the major difference between currents after the first spike and those after the second spike was a twofold reduction in sodium current. This decline in sodium current may regulate burst length for short bursts; however, it was striking that long bursts, of 10 or more spikes, were seen regularly when SK current was blocked by scyllatoxin or apamin or when both calcium current and calcium-activated potassium currents were eliminated by magnesium replacement of calcium. In the latter case, the interspike currents driving burst firing must be almost purely sodium currents, and although these may decline after the first interspike interval, they clearly remain large enough to drive subsequent spikes, at least in the absence of both BK and SK currents. It seems likely that the buildup of SK current could be a powerful feedback mechanism for terminating bursts, especially those lasting more than two or three spikes.

It was somewhat surprising to find that T-type calcium cur- 
rent carries most of the total calcium current between spikes. With voltage steps, P-type current is far larger than T-type current (Regan, 1991; McDonough and Bean, 1998); however, deactivation of P-type channels is very rapid (Regan, 1991), and the larger T-type current in the middle of the interspike interval reflects the much slower deactivation of T-type channels. In principle, current carried by T-type channels might be expected to inactivate during the burst. Indeed, such inactivation of T-type current during burst waveforms was seen with cloned $\alpha 1 \mathrm{G}$ channels, which probably underlie the T-type current in Purkinje neurons (Talley et al., 1999), when expressed in heterologous expression systems (Chemin et al., 2002). Evidently inactivation is slower for native T-type channels, because there was no reduction in current during the second interspike interval. Most likely, some inactivation does occur but is compensated for by the more negative voltage (and larger driving force) during the second interspike interval.

Large interspike currents are carried by both voltagedependent calcium channels and calcium-activated potassium channels. The exact quantitative relationship between these currents must strongly influence bursts. On average, the two opposing currents were nearly equal in the middle of the interspike interval; however, the existence of an afterdepolarization in the presence of TTX (Fig. $1 B$ ) suggests that immediately after a spike, the balance favors net inward calcium current. This is likely attributable to the very large tail currents carried by P-type channels immediately after a spike. The slower decaying calciumactivated potassium currents, on the other hand, dominate late in the interspike interval, and the overall effect of blocking calcium entry is to enhance bursting.

Why do Purkinje neurons fire all-or-none bursts whereas most neurons do not? In addition to resurgent sodium current and prominent T-type calcium current, a key factor is the fast deactivation of voltage-dependent potassium currents. Purkinje neurons have rapid repolarization and narrow spikes, consistent with large potassium currents, but they do not have prominent afterhyperpolarizations, suggesting rapid deactivation of the potassium currents. Consistent with this, in whole-cell recordings from isolated neurons and nucleated-patch and outside-out patch recordings from cell bodies of Purkinje neurons, the predominant potassium current decays with a time constant of $<1$ msec near -60 or $-70 \mathrm{mV}$ (Raman and Bean, 1999; Southan and Robertson, 2000; Martina et al., 2003). The fast deactivation is consistent with a major contribution of Kv3 family potassium channels (Martina et al., 2003).

How does the same complement of ion channels in a Purkinje neuron lead either to bursting or to tonic firing of single spikes, the other main behavior of Purkinje neurons? Resurgent sodium current appears to be important both for bursting (Raman et al., 1997) and for spontaneous tonic firing of single spikes (Khaliq et al., 2003). A crucial factor in whether a cell fires a burst or a single spike is likely to be the availability of T-type calcium current. Cells can switch from spontaneous firing of single spikes to spontaneous firing of doublets or triplets by just a small degree of hyperpolarization for interspike intervals near $-70 \mathrm{mV}$, where steady-state inactivation of T-type current is steeply voltage dependent (McDonough and Bean, 1998). SK current also regulates bursting effectively (Fig. 13) (Edgerton and Reinhart, 2003; Womack and Khodakhah, 2003). With spontaneous tonic firing, submembrane calcium may be tonically elevated, which would increase SK current and promote single spike rather than burst firing.
Burst firing is seen in various types of neurons. Even when the waveform of the bursts is very similar between cell types, however, the mechanisms of burst firing appear to differ. The all-or-none bursting in Purkinje neurons strongly resembles that elicited in subicular pyramidal neurons by short depolarizations (Jung et al., 2001), yet in subicular neurons, the primary ionic mechanism appears to be a spike-elicited calcium tail current carried by high voltage-activated calcium channels, with no evidence for a major contribution of subthreshold sodium current (Jung et al., 2001). Thus, removal of external calcium, which enhances burst firing in Purkinje neurons, eliminates all-or-none burst firing in subicular neurons (Jung et al., 2001 ) as it also does in layer 5 neocortical pyramidal neurons (Williams and Stuart, 1999).

The small net interspike current arises from the balance of much larger currents through individual conductances. How is this balance achieved, when the magnitude of individual conductances varies considerably from cell to cell? The degree of activation of different conductances between spikes depends on the precise trajectory of the voltage, and feedback mechanisms from the kinetics and voltage dependence of different currents must serve to preserve burst firing in the face of changes in individual conductances. One obvious feedback mechanism is that any reduction in calcium current (which drives depolarization after the first spike) will be accompanied by a reduction in calciumactivated potassium current (which retards depolarization). There may be less obvious feedback mechanisms based on changes in spike height or width. Also, a given pattern of firing generated by a complex combination of multiple conductances does not necessarily require a precise ratio of the different conductances but can be achieved by various different ratios (Goldman et al., 2001).

Our experiments used a reduced preparation consisting of the cell body, a small stump of proximal dendrite, and perhaps a stump of the initial segment of the axon. Burst firing in this preparation suggests that dendritic conductances are not necessary, but obviously does not rule out their participation in intact neurons. In undialyzed Purkinje neurons from mature mice, burst firing occurs spontaneously as part of a cycle of tonic, bursting, and silent periods (Womack and Khodakhah, 2002b). Purkinje neuron dendrites have a high density of calcium channels (Usowicz et al., 1992; Mouginot et al., 1997) and can form calcium spikes (Llinás and Sugimori, 1980), and burst firing could be enhanced by interspike current from dendritic calcium channels (Jaeger et al., 1997; Pouille et al., 2000). Participation of dendritic calcium channels in burst firing during complex spikes triggered by climbing fiber EPSPs has been proposed (Martinez et al., 1971). On the other hand, propagation of dendritic spikes to the soma can actually be enhanced when P-type calcium channels are blocked, perhaps by preventing activation of calciumactivated potassium channels that reduce spread of dendritic depolarization to the soma (Cavelier et al., 2002). Also, although bursts from climbing fiber stimulation are accompanied by dendritic calcium spikes, similar bursts elicited by anode break stimulation of the soma are not (Callaway and Ross, 1997). This is different from that in layer 5 pyramidal neurons, in which regenerative calcium spikes in the dendrites appear to be crucial for bursts elicited in the cell body (Williams and Stuart, 1999). Better understanding of the integration between intrinsic membrane properties of soma and dendrites will be necessary to understand the regulation of burst firing of intact Purkinje neurons. 


\section{References}

Azouz R, Jensen MS, Yaari Y (1996) Ionic basis of spike after-depolarization and burst generation in adult rat hippocampal CA1 pyramidal cells. J Physiol (Lond) 492:211-223.

Brumberg JC, Nowak LG, McCormick DA (2000) Ionic mechanisms underlying repetitive high-frequency burst firing in supragranular cortical neurons. J Neurosci 20:4829-4843.

Callaway JC, Ross WN (1997) Spatial distribution of synaptically activated sodium concentration changes in cerebellar Purkinje neurons. J Neurophysiol 77:145-152.

Cavelier P, Pouille F, Desplantez T, Beekenkamp H, Bossu JL (2002) Control of the propagation of dendritic low-threshold $\mathrm{Ca}(2+)$ spikes in Purkinje cells from rat cerebellar slice cultures. J Physiol (Lond) 540:57-72.

Chemin J, Monteil A, Perez-Reyes E, Bourinet E, Nargeot J, Lory P (2002) Specific contribution of human T-type calcium channel isotypes (alpha(1G), alpha(1H) and alpha(1I)) to neuronal excitability. J Physiol (Lond) 540:3-14.

Cingolani LA, Gymnopoulos M, Boccaccio A, Stocker M, Pedarzani P (2002) Developmental regulation of small-conductance $\mathrm{Ca}^{2+}$-activated $\mathrm{K}^{+}$ channel expression and function in rat Purkinje neurons. J Neurosci 22:4456-4467.

de Haas V, Vogel W (1989) Sodium and potassium currents recorded during an action potential. Eur Biophys J 17:49-51.

Do MT, Bean BP (2003) Subthreshold sodium currents and pacemaking of subthalamic neurons. Modulation by slow inactivation. Neuron 39:109-120.

Eccles JC, Llinas R, Sasaki K (1966) The excitatory synaptic action of climbing fibres on the Purkinje cells of the cerebellum. J Physiol (Lond) 182:268-296

Edgerton JR, Reinhart PH (2003) Distinct contributions of small and large conductance $\mathrm{Ca}^{2+}$-activated $\mathrm{K}^{+}$channels to rat Purkinje neuron function. J Physiol (Lond) 548:53-69.

Fleidervish IA, Friedman A, Gutnick MJ (1996) Slow inactivation of $\mathrm{Na}^{+}$ current and slow cumulative spike adaptation in mouse and guinea pig neocortical neurones in slices. J Physiol (Lond) 493:83-97.

Goldman MS, Golowasch J, Marder E, Abbott LF (2001) Global structure, robustness, and modulation of neuronal models. J Neurosci 21:5229-5238.

Grieco TM, Afshari FS, Raman IM (2002) A role for phosphorylation in the maintenance of resurgent sodium current in cerebellar Purkinje neurons. J Neurosci 22:3100-3107.

Gruol DL, Franklin CL (1987) Morphological and physiological differentiation of Purkinje neurons in cultures of rat cerebellum. J Neurosci 7:1271-1293.

Gruol DL, Deal CR, Yool AJ (1992) Developmental changes in calcium conductances contribute to the physiological maturation of cerebellar Purkinje neurons in culture. J Neurosci 12:2838-2848.

Haj-Dahmane S, Andrade R (1997) Calcium-activated cation nonselective current contributes to the fast afterdepolarization in rat prefrontal cortex neurons. J Neurophysiol 78:1983-1989.

Hasuo H, Phelan KD, Twery MJ, Gallagher JP (1990) A calcium-dependent slow afterdepolarization recorded in rat dorsolateral septal nucleus neurons in vitro. J Neurophysiol 64:1838-1846.

Hille B (2001a) Selective permeability: independence. In: Ion channels of excitable membranes, Ed 3, pp 453-457. Sunderland, MA: Sinauer.

Hille B (2001b) Modification of gating in voltage sensitive channels. In: Ion channels of excitable membranes, Ed 3, pp 653-656. Sunderland, MA: Sinauer.

Hodgkin AL, Huxley AF (1952) A quantitative description of membrane currents and its application to conduction and excitation in nerve. J Physiol (Lond) 117:500-544.

Huguenard JR, Prince DA (1992) A novel T-type current underlies prolonged $\mathrm{Ca}(2+)$-dependent burst firing in GABAergic neurons of rat thalamic reticular nucleus. J Neurosci 12:3804-3817.

Jacquin TD, Gruol DL (1999) $\mathrm{Ca}^{2+}$ regulation of a large conductance $\mathrm{K}^{+}$ channel in cultured rat cerebellar Purkinje neurons. Eur J Neurosci 11:735-739.

Jaeger D, De Schutter E, Bower JM (1997) The role of synaptic and voltagegated currents in the control of Purkinje cell spiking: a modeling study. J Neurosci 17:91-106.

Jahnsen H, Llinás R (1984) Ionic basis for the electro-responsiveness and oscillatory properties of guinea-pig thalamic neurones in vitro. J Physiol (Lond) 349:227-247.

Jung HY, Staff NP, Spruston N (2001) Action potential bursting in subicular pyramidal neurons is driven by a calcium tail current. J Neurosci 21:3312-3321.

Kaneda M, Wakamori M, Ito C, Akaike N (1990) Low-threshold calcium current in isolated Purkinje cell bodies of rat cerebellum. J Neurophysiol 63:1046-1051.

Kay AR, Sugimori M, Llinás R (1998) Kinetic and stochastic properties of a persistent sodium current in mature guinea pig cerebellar Purkinje cells. J Neurophysiol 80:1167-1179.

Khaliq ZM, Gouwens NW, Raman IM (2003) The contribution of resurgent sodium current to high-frequency firing in Purkinje neurons: an experimental and modeling study. J Neurosci 23:4899-4912.

Lang DG, Ritchie AK (1990) Tetraethylammonium blockade of apaminsensitive and insensitive $\mathrm{Ca} 2(+)$-activated $\mathrm{K}^{+}$channels in a pituitary cell line. J Physiol (Lond) 425:117-132.

Llinás R, Sugimori M (1980) Electrophysiological properties of in vitro Purkinje cell dendrites in mammalian cerebellar slices. J Physiol (Lond) 305:197-213.

Llinás R, Sugimori M, Simon SM (1982) Transmission by presynaptic spike-like depolarization in the squid giant synapse. Proc Natl Acad Sci USA 79:2415-2419.

Luthi A, Bal T, McCormick DA (1998) Periodicity of thalamic spindle waves is abolished by ZD7288, a blocker of $I_{\mathrm{h}}$. J Neurophysiol 79:3284-3289.

Magistretti J, Mantegazza M, Guatteo E, Wanke E (1996) Action potentials recorded with patch-clamp amplifiers: are they genuine? Trends Neurosci 19:530-534.

Magistretti J, Mantegazza M, de Curtis M, Wanke E (1998) Modalities of distortion of physiological voltage signals by patch-clamp amplifiers: a modeling study. Biophys J 74:831-842.

Martina M, Yao GL, Bean BP (2003) Properties and functional role of voltage-dependent potassium channels in dendrites of rat cerebellar Purkinje neurons. J Neurosci 23:5698-5707.

Martinez FE, Crill WE, Kennedy TT (1971) Electrogenesis of cerebellar Purkinje cell responses in cats. J Neurophysiol 34:348-356.

McDonough SI, Bean BP (1998) Mibefradil inhibition of T-type calcium channels in cerebellar Purkinje neurons. Mol Pharmacol 54:1080-1087.

Mintz IM, Bean BP (1993) Block of calcium channels in rat neurons by synthetic omega-Aga-IVA. Neuropharmacology 32:1161-1169.

Mintz IM, Venema VJ, Swiderek KM, Lee TD, Bean BP, Adams ME (1992a) P-type calcium channels blocked by the spider toxin omega-Aga-IVA. Nature 355:827-829.

Mintz IM, Adams ME, Bean BP (1992b) P-type calcium channels in rat central and peripheral neurons. Neuron 9:85-95.

Mouginot D, Bossu JL, Gahwiler BH (1997) Low-threshold Ca ${ }^{2+}$ currents in dendritic recordings from Purkinje cells in rat cerebellar slice cultures. J Neurosci 17:160-170.

Nam SC, Hockberger PE (1997) Analysis of spontaneous electrical activity in cerebellar Purkinje cells acutely isolated from postnatal rats. J Neurobiol 33:18-32.

Neher E (1992) Correction for liquid junction potentials in patch clamp experiments. Methods Enzymol 207:123-131.

Nicoll RA (1988) The coupling of neurotransmitter receptors to ion channels in the brain. Science 241:545-551.

Pape HC (1996) Queer current and pacemaker: the hyperpolarizationactivated cation current in neurons. Annu Rev Physiol 58:299-327.

Park YB (1994) Ion selectivity and gating of small conductance Ca(2+)activated $\mathrm{K}^{+}$channels in cultured rat adrenal chromaffin cells. J Physiol (Lond) 481:555-570.

Pouille F, Cavelier P, Desplantez T, Beekenkamp H, Craig PJ, Beattie RE, Volsen SG, Bossu JL (2000) Dendro-somatic distribution of calciummediated electrogenesis in Purkinje cells from rat cerebellar slice cultures. J Physiol (Lond) 527:265-282.

Raman IM, Bean BP (1997) Resurgent sodium current and action potential formation in dissociated cerebellar Purkinje neurons. J Neurosci 17:4517-4526.

Raman IM, Bean BP (1999) Ionic currents underlying spontaneous action potentials in isolated cerebellar Purkinje neurons. J Neurosci 19:1663-1674.

Raman IM, Bean BP (2001) Inactivation and recovery of sodium currents in cerebellar Purkinje neurons: evidence for two mechanisms. Biophys J 80:729-737.

Raman IM, Sprunger LK, Meisler MH, Bean BP (1997) Altered subthresh- 
old sodium currents and disrupted firing patterns in Purkinje neurons of Scn8a mutant mice. Neuron 19:881-891.

Regan LJ (1991) Voltage-dependent calcium currents in Purkinje cells from rat cerebellar vermis. J Neurosci 11:2259-2269.

Sacco T, Tempia F (2002) A-type potassium currents active at subthreshold potentials in mouse cerebellar Purkinje cells. J Physiol (Lond) 543:505-520.

Smith SL, Otis TS (2002) NO/cGMP pathway causes persistent changes in Purkinje neuron spontaneous activity. Soc Neurosci Abstr 28:146.11.

Song JH, Narahashi T (1996) Modulation of sodium channels of rat cerebellar Purkinje neurons by the pyrethroid tetramethrin. J Pharmacol Exp Ther 277:445-453.

Southan AP, Robertson B (2000) Electrophysiological characterization of voltage-gated $\mathrm{K}(+)$ currents in cerebellar basket and Purkinje cells: Kv1 and Kv3 channel subfamilies are present in basket cell nerve terminals. J Neurosci 20:114-122.

Taddese A, Bean BP (2002) Subthreshold sodium current from rapidly inactivating sodium channels drives spontaneous firing of tuberomammillary neurons. Neuron 33:587-600.

Talley EM, Cribbs LL, Lee JH, Daud A, Perez-Reyes E, Bayliss DA (1999) Differential distribution of three members of a gene family encoding low voltage-activated (T-type) calcium channels. J Neurosci 19:1895-1911.

Usowicz MM, Sugimori M, Cherksey B, Llinás R (1992) P-type calcium channels in the somata and dendrites of adult cerebellar Purkinje cells. Neuron 9:1185-1199.

Velumian AA, Zhang L, Pennefather P, Carlen PL (1997) Reversible inhibi- tion of $I_{\mathrm{K}}, I_{\mathrm{AHP}}, I_{\mathrm{h}}$ and $I_{\mathrm{Ca}}$ currents by internally applied gluconate in rat hippocampal pyramidal neurones. Pflügers Arch 433:343-350.

Wang Y, Strahlendorf JC, Strahlendorf HK (1991) A transient voltagedependent outward potassium current in mammalian cerebellar Purkinje cells. Brain Res 567:153.

Washburn DLS, Anderson JW, Ferguson A (2000) A subthreshold persistent sodium current mediates bursting in rat subfornical organ neurones. J Physiol (Lond) 529:359-371.

White G, Lovinger DM, Weight FF (1989) Transient low-threshold $\mathrm{Ca}^{2+}$ current triggers burst firing through an afterdepolarizing potential in an adult mammalian neuron. Proc Natl Acad Sci USA 86:6802-6806.

Williams SR, Stuart GJ (1999) Mechanisms and consequences of action potential burst firing in rat neocortical pyramidal neurons. J Physiol (Lond) 521:467-482.

Williams SR, Christensen SR, Stuart GJ, Hausser M (2002) Membrane potential bistability is controlled by the hyperpolarization-activated current $I(\mathrm{H})$ in rat cerebellar Purkinje neurons in vitro. J Physiol (Lond) 539:469-483.

Womack MD, Khodakhah K (2002a) Characterization of large conductance $\mathrm{Ca}^{2+}$-activated $\mathrm{K}^{+}$channels in cerebellar Purkinje neurons. Eur J Neurosci 16:1214-1222.

Womack MD, Khodakhah K (2002b) Active contribution of dendrites to the tonic and trimodal patterns of activity in cerebellar Purkinje neurons. J Neurosci 22:10603-10612.

Womack MD, Khodakhah K (2003) Somatic and dendritic smallconductance calcium-activated potassium channels regulate the output of cerebellar Purkinje neurons. J Neurosci 23:2600-2607. 